\title{
Catalysis and mechanistic studies of ruthenium and osmium on synthesis of anthranilic acids
}

\author{
P. Karthikeyan ${ }^{a}$, Rajenahally V. Jagadeesh ${ }^{a *}$, Y. Sree Sandhya ${ }^{a}$, \\ Puttaswamy $^{b}$, P. Nithya ${ }^{a}$, S. Senthil Kumar ${ }^{a}$ and P.R. Bhagat ${ }^{a}$
}

Ruthenium, osmium and ruthenium + osmium catalyzed synthetic methodology was developed for the synthesis of anthranilic acids from indoles in good to excellent yields using bromamine-B in alkaline acetonitrile-water (1:1) at $313 \mathrm{~K}$. Detailed catalysis studies of ruthenium, osmium and the mixture of both were carried out for the synthetic reactions. The positive synergistic catalytic activity of Ru(III) + Os(VIII) was observed to a large extent with the activity greater than the sum of their separate catalytic activities. Detailed kinetic and mechanistic investigations for each catalyzed reactions were carried out. The kinetic pattern and mechanistic picture of each catalyzed reaction were found to be different for each catalyst and to obey the underlying rate laws:

$$
\begin{aligned}
& \text { rate }=k[\mathrm{BAB}]_{t}[\text { Indole }][\mathrm{Ru}(\mathrm{III})]^{x}\left[\mathrm{OH}^{-}\right]^{y} \\
& \text { rate }=k[\mathrm{BAB}]_{t}[\text { Indole }][\mathrm{Os}(\mathrm{VIII})]\left[\mathrm{OH}^{-}\right]^{y} \\
& \text { rate }=k[\mathrm{BAB}]_{t}[\text { Indole }]^{\mathrm{O}}[\mathrm{Ru}(\mathrm{III})+\mathrm{Os}(\mathrm{VIII})]\left[\mathrm{OH}^{-}\right]^{y}
\end{aligned}
$$

where, $x, y<1$. The reactions were studied at different temperatures and the activation parameters were evaluated for each catalyzed reaction. Under the identical set of experimental conditions, the kinetics of all the three catalyzed reactions were compared with uncatalyzed reactions, revealing that the catalyzed reactions were 6- to 42-fold faster. The catalytic efficiency of aforementioned catalysts followed the order: $\mathrm{Ru}(\mathrm{III})+\mathrm{Os}(\mathrm{VIII})>\mathrm{Os}(\mathrm{VIII})>\mathbf{R u}(\mathrm{III})$. This trend may be attributed to the different d-electronic configuration of the catalysts. The proposed mechanisms and the rigorous kinetic models derived give results that fit well with the experimental data in each catalyzed reaction. Copyright (c) 2010 John Wiley \& Sons, Ltd.

Supporting information may be found in the online version of this article.

Keywords: $\mathrm{Ru}(\mathrm{III}) / \mathrm{Os}(\mathrm{VIII}) / \mathrm{Ru}(\mathrm{III})+\mathrm{Os}(\mathrm{VIII})$ catalysis; anthranilic acids; indoles; reaction mechanism; bromamine-B

\section{Introduction}

The importance of anthranilic acids resides in their well established anti-inflammatory activity and their potential uses as intermediates for the production of dyes, pigments and saccharin. Anthranilic acid and its ester derivatives are used in preparing perfumes, pharmaceuticals and UV-absorber as well as corrosion inhibitors for metals and mould inhibitors in soy sauce. Thus, many derivatives of anthranilic acids have been synthesized with the objective of discovering new pharmacological agents. ${ }^{[1-4]}$ Because of the versatile properties and pharmaceutical applications of anthranilic acids, synthesis of anthranilic acids is an important task for exploring convenient and efficient methodologies. There are several reports available in the literature about the synthesis of anthranilic acids with different approaches. ${ }^{[4,5]}$ However, there is still a need to introduce safer and more efficient reagents including favorable methods for the synthesis of anthranilic acids.

Synthetic methodology, as the building block of organic synthesis, continuously seeks new reagents, better reaction conditions and more efficient and selective methods. In this regard, a large group of compounds entitled sodium $\mathrm{N}$-haloarenesulfonamidates (organic haloamines) are widely used in fine organic synthesis. ${ }^{[6,7]}$ $\mathrm{N}$-haloamines act as good oxidants and reagents both in alkaline and acidic media, and have been widely used for the oxidation and synthesis of variety of organic and bio molecules. ${ }^{[7-9]}$
Bromamine- $\mathrm{B}\left(\mathrm{C}_{6} \mathrm{H}_{5} \mathrm{SO}_{2} \mathrm{NBrNa} .1 .5 \mathrm{H}_{2} \mathrm{O}\right.$ or $\mathrm{PhSO} 2 \mathrm{NBrNa}$ or $\left.\mathrm{BAB}\right)$, the bromine derivative of sulfonamide, is gaining importance as an oxidant and reagent for the synthesis of a variety of organic molecules. Although the mechanistic aspects of many of haloamine reactions have been well documented, ${ }^{[9-12]}$ similar studies on bromine analogu are sparse. In view of these facts, there is a considerable scope for the study with BAB to achieve a better insight into the speciation of $B A B$ reaction models and to understand its redox chemistry in solutions.

In recent times, studies on the use of transition metal ions as catalysts in many synthetic and redox reactions have been gaining interest. ${ }^{[13-15]}$ The catalytic activities are due to the existence of variable oxidation states, as a consequence of partially filled $\mathrm{d}$ or $\mathrm{f}$ orbitals. Their ability to form both $\sigma$ and $\pi$ bonds with other moieties or ligands is one of the chief facts for imparting catalytic

\footnotetext{
* Correspondence to: Rajenahally V. Jagadeesh, Division of Organic Chemistry, School of Advanced Sciences, VIT University, Vellore-632014, India.

E-mail:rvjdeesh@yahoo.com

a Division of Organic Chemistry, School of Advanced Sciences, VIT University, Vellore-632014, India

b Department of Chemistry, Bangalore University, Central College Campus, Bangalore-560001, India
} 


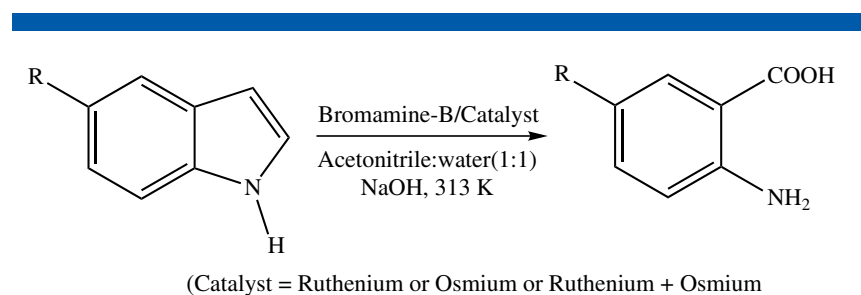

Scheme 1. Catalyzed synthesis of anthranilic acids.

properties to transition metals as well as their complexes. Most of the d-block elements show characteristic interligand migration reactions and such a process forms one of the most important types of reactions in homogeneous catalysis. Ruthenium (III) chloride $[\mathrm{Ru}(\mathrm{III})]$ and $\mathrm{Os}(\mathrm{VIII})$ oxide $[\mathrm{Os}(\mathrm{VIII})]$ have been widely used as homogeneous catalysts in various redox reactions. ${ }^{[15-19]}$ The catalytic effect of $\mathrm{Ru}(\mathrm{III})$ and $\mathrm{Os}(\mathrm{VIII})$ on various reactions is well known, but sparse information is available about $\mathrm{Ru}(\mathrm{III})$ + Os(VIII) mixed catalyst. Hence in the present work, we used $\mathrm{Ru}(\mathrm{III})$ and $\mathrm{Os}(\mathrm{VIII})$, both alone and in mixtures as a catalyst. The main objective of the present study is the development of catalytic methodology for the synthesis of anthranilic acids and the exploration of catalytic efficiency and mechanism of $\mathrm{Ru}(\mathrm{III})$, $\mathrm{Os}(\mathrm{VIII})$ and $\mathrm{Ru}(\mathrm{III})+\mathrm{Os}(\mathrm{VIII})$ mixture and also synergism of $\mathrm{Ru}(\mathrm{III})$ $+\mathrm{Os}(\mathrm{VIII})$ catalyst on the title reaction.

The wide range of applications of anthranilic acids and the usefulness of transition metals catalysis in organic reactions instigated us to carry out the title reaction to develop a protocol for the synthesis of anthranilic acids from indoles with an interest in studying the reaction mechanism and kinetics. By keeping above points in mind, we report herein a new and simple method for the preparation of anthranilic acids from indoles using bromamine-B and ruthenium/osmium catalyst (Scheme 1).

\section{Experimental}

\section{Materials}

Melting points were determined on X-4 apparatus and are uncorrected. IR spectra were obtained using a Shimadzu FTIR8900 spectrometer. Mass spectrometry data were obtained on a 17A Shimadzu gas chromatograph with a QP-5050A Shimadzu mass spectrometer. The mass spectrum was obtained using the electron impact ionization technique. Indole and substituted indoles (Lancaster and Sigma Aldrich), were of acceptable grade of purity and used as received. Aqueous solutions of the indoles were prepared by dissolution in aqueous acetonitrile $(1: 1$ water-acetonitrile) and were employed for the kinetic study. A 0.1
M stock solutions of $\mathrm{RuCl}_{3}$ (Merck) was prepared in $0.01 \mathrm{~mol} \mathrm{dm}$ $\mathrm{HCl}$ in order to avoid the hydrolysis of $\mathrm{RuCl}_{3}$ in water. The 0.1 $\mathrm{M} \mathrm{OsO}_{4}$ (Merck) stock solution was prepared in $0.01 \mathrm{~mol} \mathrm{dm}^{-3}$ $\mathrm{NaOH}$ to retain the stable oxidation state $(+8)$ of Os without any formation of aquo complex with water. Allowances were made for the amount of $\mathrm{NaOH}$ and $\mathrm{HCl}$ present in the catalyst solutions while preparing solutions for kinetic runs. Solvent isotope studies were made with $\mathrm{D}_{2} \mathrm{O}$ (99.4\%) supplied by Bhabha Atomic Research Center, Mumbai, India. Reagent-grade chemicals and doubledistilled water were used throughout. Bromamine-B was prepared by the known procedure. ${ }^{[16]}$

\section{Preparation of Bromamine-B}

Bromamine- $B$ was prepared ${ }^{[16]}$ by the partial debromination of dibromamine-B (DBB), which was obtained as follows. Pure chlorine was bubbled through an aqueous solution of chloramine$\mathrm{B}(30 \mathrm{~g}$ in $560 \mathrm{ml}$ of water) and liquid bromine $(6 \mathrm{ml})$ was added drop-wise with constant stirring. The resulting yellow precipitate of dibromamine-B (DBB) was thoroughly washed with water, filtered under suction and dried in a desiccator. DibromamineB $(31.5 \mathrm{~g})$ was digested in batches with constant stirring in $50 \mathrm{ml}$ of $4 \mathrm{~mol} \mathrm{dm}^{-3} \mathrm{NaOH}$. The mass obtained was cooled in ice, filtered under suction and the product (BAB) was dried over anhydrous calcium chloride. The purity of bromamine$B$ was assayed iodometrically to determine the active halogen content. Aqueous solutions of the oxidant were standardized by iodometric procedure and preserved in brown bottles to prevent photochemical deterioration. Bromamine- $B$ was confirmed by mass spectral analysis.

\section{Reaction Stoichiometry}

Reaction mixtures containing varying ratios of $B A B$ to indoles in the presence of $2.0 \times 10^{-3} \mathrm{~mol} \mathrm{dm}^{-3} \mathrm{NaOH}$ and $2.0 \times 10^{-6}$ catalyst were equilibrated at $313 \mathrm{~K}$ for $24 \mathrm{~h}$. Determination of unreacted $B A B$ in reaction mixture showed that 1 mole of indole consumed 3 moles of $B A B$ in all the three catalyzed reactions, confirming the stoichiometry in Scheme 2.

\section{Synthesis of Anthranilic Acids}

To a stirred solution of indoles (10 mmol), bromamine-B (30 mmol) in alkaline $(20 \mathrm{mmol} \mathrm{NaOH})$ acetonitrile-water $(1: 1)$ mixture $(20 \mathrm{ml})$, catalyst $(2 \mathrm{mmol})$ was added and the mixture was heated at $313 \mathrm{~K}$ for $3-6 \mathrm{~h}$. The reaction progress was monitored by TLC. After completion of the reaction, the reduction product of bromamine- $\mathrm{B}$, benzenesulfonamide $\left(\mathrm{PhSO}_{2} \mathrm{NH}_{2}\right)$ was extracted

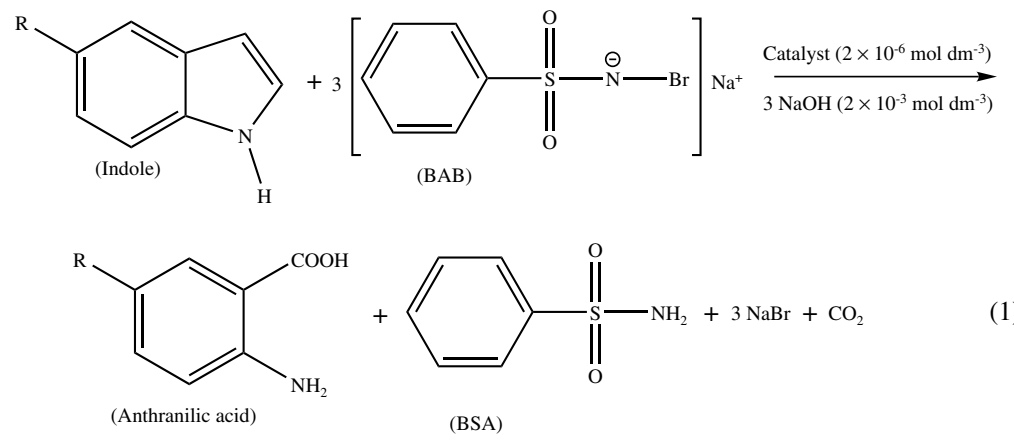

Scheme 2. Stoichiometic equation. 
Table 1. Synthesis of anthranilic acids from indoles

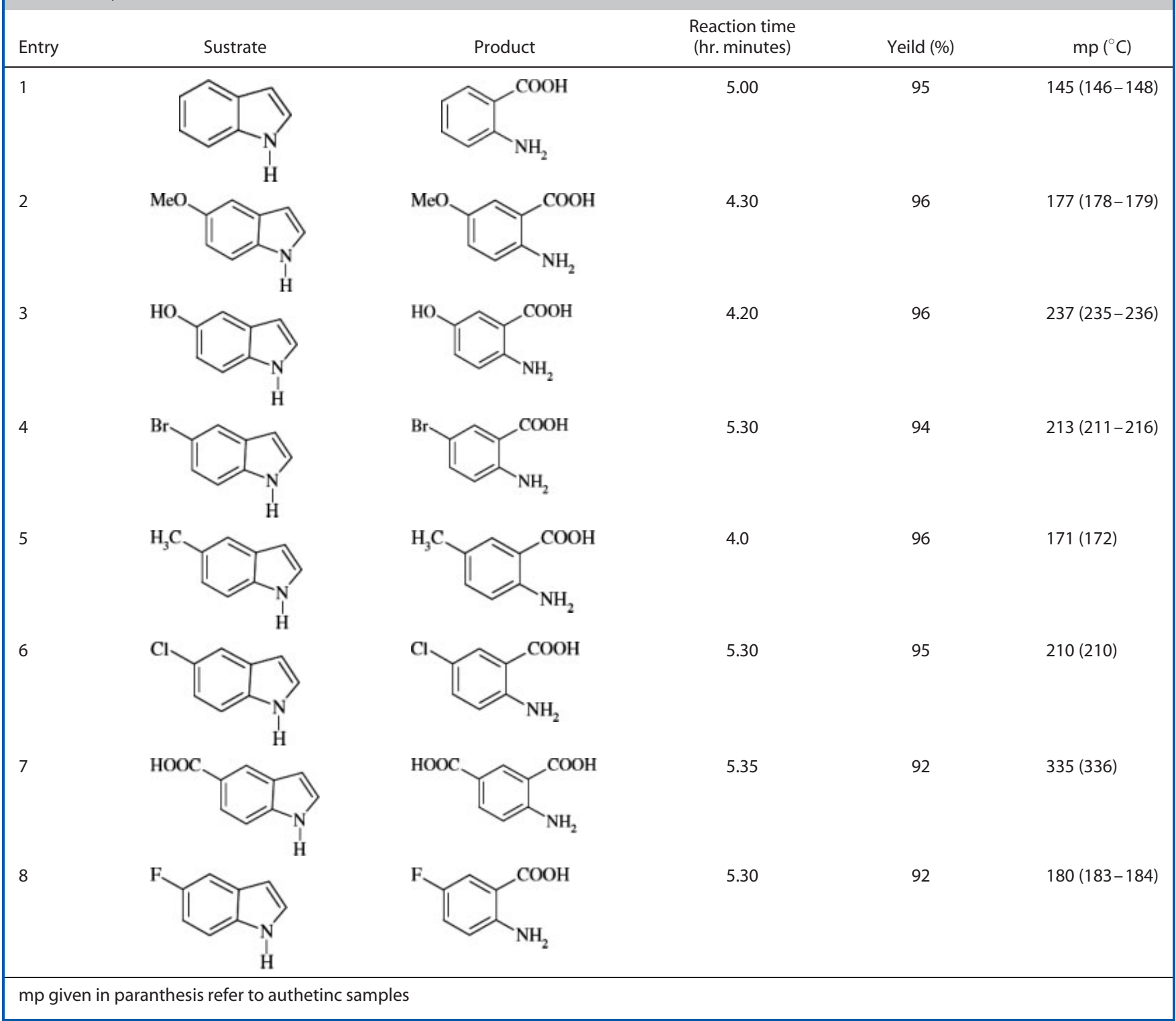

with ethyl acetate, identified by TLC and confirmed by mass spectral analysis. The aqueous part of the reaction mixture was neutralized with acid, the solvent was evaporated under reduced pressure and the residue was dissolved in dichloromethane. The dichloromethane layer was washed twice with water and dried over sodium sulfate. The solvent was evaporated under reduced pressure and the residue thus obtained was purified by passing through a short silica gel column using dichloromethane as eluent. Evaporation of the solvent yielded anthranilic acids around 95\% yield. Alternatively, after extracting out benzenesulfonamide, the aqueous layer was neutralized with acid and the anthranilic acids are estimated as their zinc anthranilates. The procedure for the estimation is as follows: anthranilate was precipitated as its zinc salt. ${ }^{[20]}$ To the reaction mixture, a calculated volume of $1 \mathrm{~mol} \mathrm{dm}^{-3}$ $\mathrm{HCl}$ was added, followed by $10 \mathrm{ml}$ of $\mathrm{pH} 5.0$ buffer and $10 \mathrm{ml}$ of $1 \%$ zinc sulfate. The precipitate formed was filtered, dried at $105-110^{\circ} \mathrm{C}$ and weighed, and the recovery of $\left(\mathrm{C}_{7} \mathrm{H}_{6} \mathrm{O}_{2} \mathrm{~N}\right)_{2} \mathrm{Zn}$ was found be around $95 \%$. The reaction times and yields are given in Table 1 . The products were identified by TLC and melting point by comparison with authentic samples. Further, the compounds were confirmed by mass spectral analysis.

\section{Kinetic Measurements}

The detailed kinetic experiments were made with respect to indole as model compounds. The reactions were carried out under pseudo first-order conditions with a known excess of [Indole]。 over $[\mathrm{BAB}]_{0}$ at $313 \mathrm{~K}$. The reaction was carried out in stoppered Pyrex boiling tubes whose outer surfaces were coated black to eliminate photochemical effects. For each run, requisite amounts of solutions of indole, $\mathrm{NaOH}$, catalyst and aqueous acetonitrile ( $1: 1$ water-acetonitrile; to keep the total volume constant for all runs) were introduced in to the tube and thermostated at $313 \mathrm{~K}$ until thermal equilibrium was attained. A measured amount of $B A B$ solution, also thermostated at the same temperature, was rapidly added with stirring to the mixture in the tube. The progress of the reaction was monitored by the iodometric determination of unreacted $B A B$ in aliquots $(5 \mathrm{ml}$ each) of the reaction mixture 
withdrawn at different intervals of time. The course of the reaction was studied for at least two half-lives. The pseudo first-order rate constants $\left(k^{\prime}\right)$ calculated from the linear plots of log $[B A B]$ vs time were reproducible within $\pm 5 \%$.

\section{Results}

Synthesis of anthranilic acid and substituted anthranilic acids was achieved using catalytic amounts of ruthenium, osmium and a mixture of both in acetonitrile-water $(1: 1)$ at $40^{\circ} \mathrm{C}$ by bromamine$B$ with $1: 3$ indole-bromamine- $B$ ratio in the presence of alkali. The products and the yields were summarized in Table 1. In general substrates containing electron-donating moieties were found to be slightly more reactive and required shorter reaction times compared to substrates containing electron-withdrawing groups.

The synthesis of anthranilic acids from indoles proceeds with the formation of isatins as the intermediates. Indoles first utilize 2 moles of bromamine- $B$ to form isatins. Thus formed isatins consume another mole of bromamine- $B$ to yield the ultimate and desired compounds, anthranilic acids. The detailed mechanisms for reactions are shown in Schemes 4, 6 and 8.

The reactions were studied in various solvents (acetonitrile, 1, 2dichloromethane, ethanol and acetonitrile-water $(1: 1)$ mixture). The mixture of acetonitrile-water $(1: 1)$ was found to be the best solvent system, perhaps due to the dielectric constant and the solubility of the reactants. Indoles are not very soluble in water, but markedly soluble in acetonitrile-water mixture. Moreover the organic haloamines furnish different species better in aqueous (water) medium rather than in organic medium. For all these reasons acetonitrile-water with a $1: 1$ ratio system was the better choice of solvent system in the present synthetic study. The reactions were found to be highly dependent upon the $\mathrm{pH}$ of the system. To evaluate the effect of $\mathrm{pH}$, the reactions were carried out under similar experimental conditions at different $\mathrm{pHs}$ using $\mathrm{NaOH}$. At neutral $\mathrm{pH}$, the oxidation reactions were found to be very slow. Reaction rates increase with increasing in $\mathrm{pH}$ (addition of $\mathrm{NaOH}$ ). This behavior of the reaction is attributed to the dissociation of bromamine- $B$ in aqueous medium by furnishing different oxidizing species. This behavior of dissociation of bromamine- $\mathrm{B}$ is well explained in the Discussion. Because of the increase rate in the presence of $\mathrm{NaOH}$, the reactions were carried out at $2.0 \times 10^{-3} \mathrm{~mol} \mathrm{dm}^{-3} \mathrm{NaOH}$. The kinetics of the oxidative conversion of indole by $B A B$ was investigated at several initial concentrations of the reactants in $\mathrm{NaOH}$ medium in presence of $\mathrm{Ru}(\mathrm{III}), \mathrm{Os}(\mathrm{VIII})$ and Ru(III) + Os(VIII) mixture catalysts at $313 \mathrm{~K}$ under identical experimental conditions.

\section{Effect of Varying Reactant Concentrations on the Rate}

With the indole in excess at constant [Indole $]_{0},[\mathrm{NaOH}]$, [catalyst] and temperature, plots of log $[B A B]$ vs time were linear, indicating a first-order dependence of the rate on $[B A B]_{0}$ in all the three catalyzed reactions. The pseudo first-order rate constants $\left(k^{\prime}\right)$ are recorded in Table 2 . Further these $k^{\prime}$ values were unaffected by the variation of $[B A B]_{0}$, confirming the first-order dependence of the rate on $[B A B]_{0}$. Under the same experimental conditions, the rate of the reaction increased with increase in [Indole] for $\mathrm{Ru}(\mathrm{III})$ and Os(VIII)-catalyzed reactions and plots of log $k^{\prime}$ vs log [Indole] (Fig. 1) were found to be linear with unit slopes, indicating firstorder dependence on $[\mathrm{Ru}(\mathrm{III})]$ and $[\mathrm{Os}(\mathrm{VIII})]$ catalysts. However, the order with respect to $\mathrm{Ru}(\mathrm{III})+\mathrm{Os}(\mathrm{VIII})$ catalyst was found to be zero order. These results are given in Table 2 .
Table 2. Effect of varying reactant concentrations on the reaction rate at $313 \mathrm{~K}$

\begin{tabular}{|c|c|c|c|c|}
\hline \multirow[b]{2}{*}{$\begin{array}{l}10^{4}[\mathrm{BAB}]_{\circ} \\
\left(\mathrm{mol} \mathrm{dm}^{-3}\right)\end{array}$} & \multirow[b]{2}{*}{$\begin{array}{l}\left.10^{3} \text { [Indole }\right]_{\circ} \\
\left(\mathrm{mol} \mathrm{dm}^{-3}\right)\end{array}$} & \multicolumn{3}{|c|}{$10^{4} k^{\prime}\left(s^{-1}\right)$} \\
\hline & & $\mathrm{Ru}(\mathrm{III})$ & Os(VIII) & $\begin{aligned} & \mathrm{Ru}(\mathrm{III}) \\
+ & \mathrm{Os}(\mathrm{VIII})\end{aligned}$ \\
\hline 0.2 & 1.0 & 3.30 & 6.75 & 21.8 \\
\hline 0.5 & 1.0 & 3.19 & 6.67 & 21.9 \\
\hline 1.0 & 1.0 & 3.21 & 6.70 & 21.7 \\
\hline 2.0 & 1.0 & 3.28 & 6.69 & 22.0 \\
\hline 4.0 & 1.0 & 3.16 & 6.77 & 21.5 \\
\hline 1.0 & 0.2 & 0.81 & 1.42 & 21.2 \\
\hline 1.0 & 0.5 & 1.60 & 3.32 & 21.9 \\
\hline 1.0 & 1.0 & 3.21 & 6.70 & 21.7 \\
\hline 1.0 & 2.0 & 6.50 & 14.0 & 21.4 \\
\hline 1.0 & 4.0 & 13.0 & 27.5 & 22.0 \\
\hline
\end{tabular}

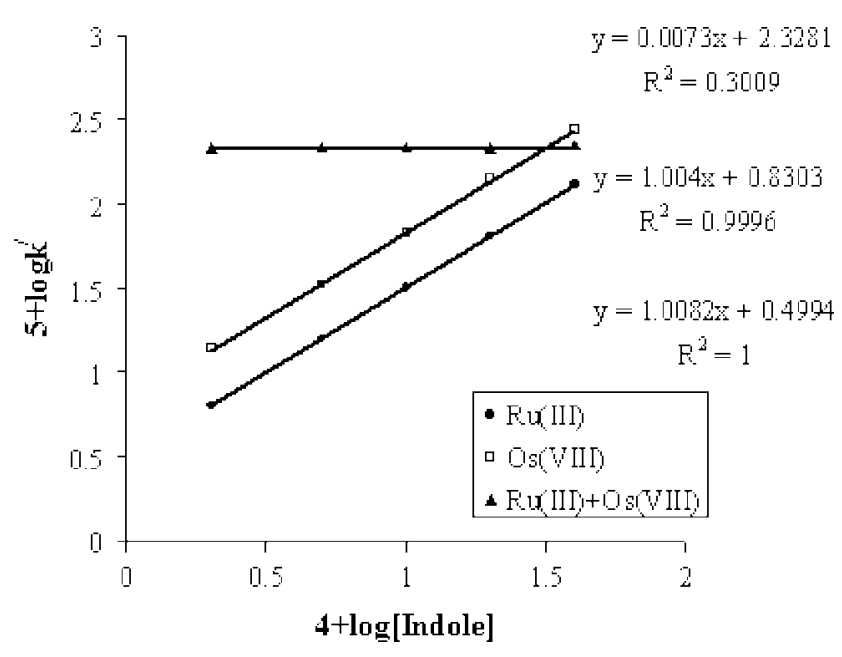

Figure 1. Plots of log $\mathrm{k}^{\prime}$ versus log[Indole].

\section{Effect of Varying $\mathrm{NaOH}$ and Catalyst Concentrations on the Rate}

The kinetic experiments showed that the rate is unaffected with aqueous acetonitrile markedly. The reactions were carried out with different amounts of acetonitrile and it was found that the rate is not affected significantly by acetonitrile. However, rate is significantly affected by alkali. The rate of the reaction increased with increase in $[\mathrm{NaOH}]$ in all cases (Table 3). The log-log plots of rate vs $[\mathrm{NaOH}]$ (Fig. 2) showed that the orders in $[\mathrm{NaOH}]$ were less than unity, suggesting a fractional-order dependence on $\left[\mathrm{OH}^{-}\right]$in all three catalyzed reactions. The reaction rate increased with increase in [catalyst] in all the cases (Table 3). The order with respect to $[\mathrm{Ru}(\mathrm{III})]$ was found to be fractional but it was found to be unity for $[\mathrm{Os}(\mathrm{VIII})]$ and $[\mathrm{Ru}(\mathrm{III})+\mathrm{Os}(\mathrm{VIII})]$ catalysts. This clearly indicates a fractional-order dependence on [Ru(III)], and first-order dependence on $[\mathrm{Os}(\mathrm{VIII})]$ and $[\mathrm{Ru}(\mathrm{III})+\mathrm{Os}(\mathrm{VIII})]$ catalysts. The plots of $\log k^{\prime}$ vs log [catalyst] are presented in Fig. 3. 
Table 3. Effect of varying $\mathrm{NaOH}$ and catalyst concentrations on the reaction rate at $313 \mathrm{~K}$

\begin{tabular}{|c|c|c|c|c|}
\hline \multirow[b]{2}{*}{$\begin{array}{l}10^{3}[\mathrm{NaOH}] \\
\left(\mathrm{mol} \mathrm{dm}^{-3}\right)\end{array}$} & \multirow[b]{2}{*}{$\begin{array}{l}10^{6} \text { [catalyst] } \\
\left(\mathrm{mol} \mathrm{dm}^{-3}\right)\end{array}$} & \multicolumn{3}{|c|}{$10^{4} k^{\prime}\left(s^{-1}\right)$} \\
\hline & & $\mathrm{Ru}(\mathrm{III})$ & Os(VIII) & $\begin{aligned} & \mathrm{Ru}(\mathrm{III}) \\
+ & \mathrm{Os}(\mathrm{VIII})\end{aligned}$ \\
\hline 0.5 & 2.0 & 1.5 & 3.32 & 10 \\
\hline 1.0 & 2.0 & 2.02 & 4.80 & 13.5 \\
\hline 2.0 & 2.0 & 3.21 & 6.70 & 21.7 \\
\hline 4.0 & 2.0 & 5.00 & 9.00 & 31.6 \\
\hline 6.0 & 2.0 & 6.96 & 11.4 & 40.0 \\
\hline 2.0 & 0.5 & 1.1 & 1.72 & 5.00 \\
\hline 2.0 & 1.0 & 1.71 & 3.26 & 10.0 \\
\hline 2.0 & 2.0 & 3.21 & 6.70 & 21.7 \\
\hline 2.0 & 4.0 & 6.38 & 14.3 & 43.0 \\
\hline 2.0 & 8.0 & 10.0 & 28.5 & 88.0 \\
\hline
\end{tabular}

\section{Effect of Varying lonic Strength of the Medium on the Rate}

An increase in ionic strength of a reaction system by addition of $\mathrm{NaClO}_{4}$ showed a negligible effect on the reaction rate in the case of $\mathrm{Ru}(\mathrm{III})$. However, the rate of the reaction increased with increasing ionic strength in the case of Os(VIII) catalysis and the rate decreased in the case of $\mathrm{Ru}(\mathrm{III})+\mathrm{Os}(\mathrm{VIII})$ catalysis. Plots of log $k^{\prime}$ vs $I^{1 / 2}$ were found to be linear with slopes +0.50 and -1.60 in $\mathrm{Os}(\mathrm{VIII})$ and $\mathrm{Ru}(\mathrm{III})+\mathrm{Os}(\mathrm{VIII})$ catalysis respectively (Table 4). Hence, the ionic strength of the medium was maintained at a constant concentration of $0.30 \mathrm{~mol} \mathrm{dm}^{-3}$ of $\mathrm{NaClO}_{4}$ in the case of Os(VIII) and $\mathrm{Ru}(\mathrm{III})+\mathrm{Os}(\mathrm{VIII})$ catalysis for kinetic runs in order to swamp the reaction.

\section{Effect of Solvent Isotope on the Rate}

Studies of the reaction rate in $\mathrm{D}_{2} \mathrm{O}$ medium for $\mathrm{Ru}(\mathrm{III}), \mathrm{Os}(\mathrm{VIII})$ and $\mathrm{Ru}(\mathrm{III})+\mathrm{Os}(\mathrm{VIII})$ catalyzed reactions revealed that $k^{\prime}\left(\mathrm{H}_{2} \mathrm{O}\right)$ was equal to $3.20 \times 10^{-4}, 6.70 \times 10^{-4}$ and $21.7 \times 10^{-4}$ and $k^{\prime}\left(D_{2} O\right)$ $=4.50 \times 10^{-4}, 8.45 \times 10^{-4}$ and $29.1 \times 10^{-4}$, respectively. The solvent isotope effect, $k^{\prime}\left(\mathrm{H}_{2} \mathrm{O}\right) / K^{\prime}\left(\mathrm{D}_{2} \mathrm{O}\right)$ was found to be $0.71,0.79$ and 0.75 for the three catalyzed reactions. These results are given Table 5.

\section{Effect of Varying Temperature on the Rate}

The reactions were studied at different temperatures (303-323 K), keeping other experimental conditions constant. From the linear Arrhenius plots of $\log k^{\prime}$ vs $1 / T$, values of activation parameters

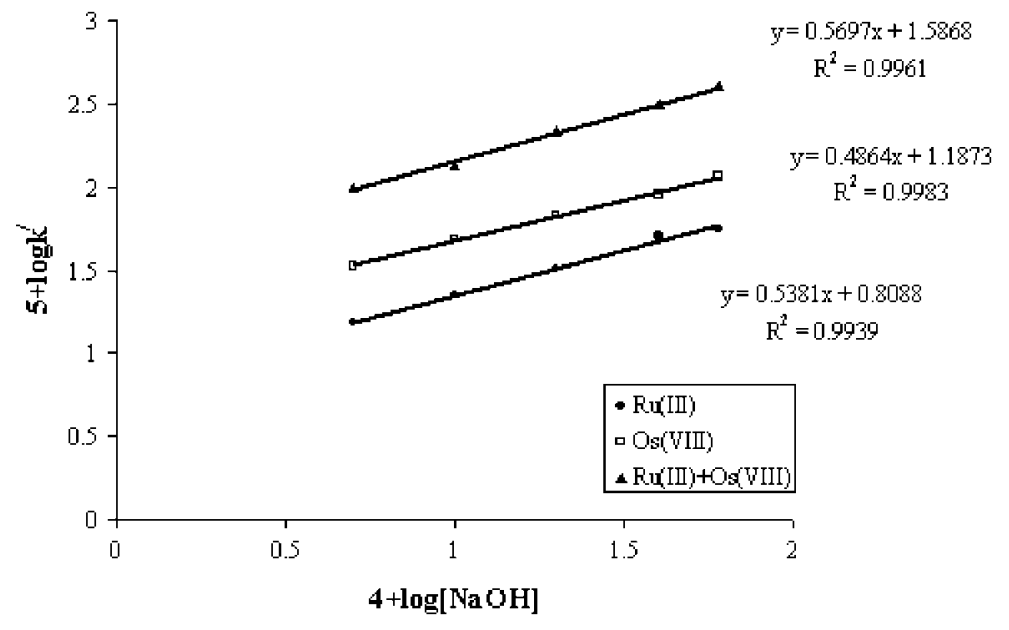

Figure 2. Plots of logk' versus $\log [\mathrm{NaOH}]$.

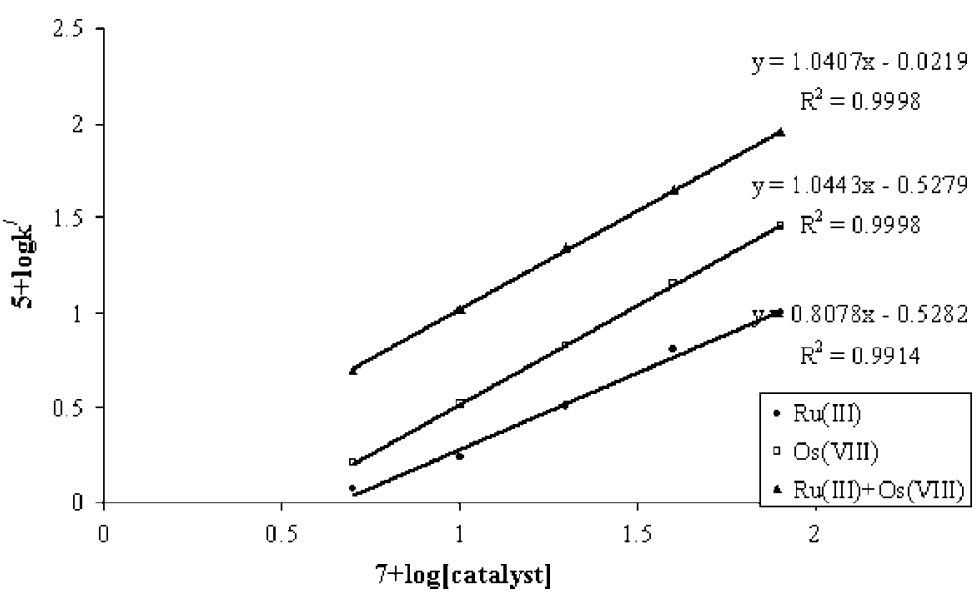

Figure 3. Plots of logk' versus log[catalyst]. 
Table 4. Effect of varying ionic strength of the medium on the reaction rate at $313 \mathrm{~K}$

\begin{tabular}{lccc} 
& \multicolumn{3}{c}{$10^{4} k^{\prime}\left(\mathrm{s}^{-1}\right)$} \\
\cline { 2 - 4 } $\begin{array}{l}\text { lonic strength }(I) \\
\left.(\mathrm{mol} \mathrm{dm})^{-3}\right)\end{array}$ & $\mathrm{Ru}(\mathrm{III})$ & $\mathrm{Os}(\mathrm{VIII})$ & $\begin{array}{c}\mathrm{Ru}(\mathrm{III}) \\
+ \text { Os(VIII) }\end{array}$ \\
\hline 0.1 & 3.28 & 5.00 & 48.9 \\
0.2 & 3.19 & 6.00 & 28.8 \\
0.3 & 3.21 & 6.7 & 21.7 \\
0.4 & 3.30 & 7.60 & 14.8 \\
0.5 & 3.17 & 8.70 & 11.2 \\
\hline
\end{tabular}

$[B A B]_{0}=1.0 \times 10^{-4} \mathrm{~mol} \mathrm{dm}^{-3} ;[\text { Indole }]_{0}=1.0 \times 10^{-3} \mathrm{~mol} \mathrm{dm}^{-3} ;$ $[\mathrm{NaOH}]=2.0 \times 10^{-3} \mathrm{~mol} \mathrm{dm}^{-3} ;$ [catalyst $]=2.0 \times 10^{-6} \mathrm{~mol} \mathrm{dm}^{-3}$.

Table 5. Effect of solvent isotope on the rate at $313 \mathrm{~K}$

\begin{tabular}{lccc} 
& $k^{\prime}$ (Water) & $k^{\prime}\left(\mathrm{D}_{2} \mathrm{O}\right)$ & $\begin{array}{c}k^{\prime}\left(\mathrm{H}_{2} \mathrm{O}\right) / K^{\prime} \\
\left(\mathrm{D}_{2} \mathrm{O}\right)\end{array}$ \\
\hline $\mathrm{Ru}(\mathrm{III})$ & $3.20 \times 10^{-4} \mathrm{~s}^{-1}$ & $4.50 \times 10^{-4} \mathrm{~s}^{-1}$ & 0.71 \\
$\mathrm{Os}(\mathrm{VIII})$ & $6.70 \times 10^{-4} \mathrm{~s}^{-1}$ & $8.45 \times 10^{-4} \mathrm{~s}^{-1}$ & 0.79 \\
$\mathrm{Ru}(\mathrm{III})+\mathrm{Os}$ (VIII) & $21.7 \times 10^{-4} \mathrm{~s}^{-1}$ & $29.1 \times 10^{-4} \mathrm{~s}^{-1}$ & 0.75 \\
\hline
\end{tabular}

$[B A B]_{\circ}=1.0 \times 10^{-4} \mathrm{~mol} \mathrm{dm}^{-3} ;$ [ndole $]_{\circ}=1.0 \times 10^{-3} \mathrm{~mol} \mathrm{dm}^{-3} ;$ $[\mathrm{NaOH}]=2.0 \times 10^{-3} \mathrm{~mol} \mathrm{dm}^{-3} ;$ [catalyst $]=2.0 \times 10^{-6} \mathrm{~mol} \mathrm{dm}^{-3}$; $I=0.3 \mathrm{~mol} \mathrm{dm}^{-3}$ [in the case of Os(VIII) and Ru(III) + Os(VIII) catalysis].

Table 6. Temperature dependence and values of composite activation parameters for the synthesis of anthranilic acid by $B A B$ in the presence and absence of catalyst

\begin{tabular}{|c|c|c|c|c|}
\hline \multirow[b]{2}{*}{ Temperature (K) } & \multicolumn{4}{|c|}{$10^{4} k^{\prime}\left(s^{-1}\right)$} \\
\hline & $\mathrm{Ru}(\mathrm{III})$ & Os(VIII) & $\begin{aligned} & \mathrm{Ru}(\mathrm{III}) \\
+ & \mathrm{Os}(\mathrm{VIII})\end{aligned}$ & Uncatalyzed \\
\hline 303 & 1.31 & 3.34 & 14.0 & 0.18 \\
\hline 308 & 2.01 & 5.01 & 17.8 & 0.32 \\
\hline 313 & 3.21 & 6.70 & 21.7 & 0.52 \\
\hline 318 & 5.26 & 10.0 & 26.4 & 0.90 \\
\hline 323 & 7.01 & 13.4 & 33.5 & 1.58 \\
\hline$E_{\mathrm{a}}\left(\mathrm{kJ} \mathrm{mol}^{-1}\right)$ & 70.3 & 52.3 & 29.7 & 85.4 \\
\hline$\Delta H^{\neq}\left(\mathrm{kJ} \mathrm{mol}^{-1}\right)$ & 67.4 & 49.8 & 26.7 & 82.8 \\
\hline$\Delta G^{\neq}\left(\mathrm{kJ} \mathrm{mol}^{-1}\right)$ & 94.6 & 92.6 & 90.0 & 98.4 \\
\hline$\Delta S^{\neq}\left(\mathrm{JK}^{-1} \mathrm{~mol}^{-1}\right)$ & -80.0 & -141 & -206 & -52.7 \\
\hline $\log A$ & 8.62 & 5.85 & 2.45 & 10.4 \\
\hline \multicolumn{5}{|c|}{$\begin{array}{l}{[\mathrm{BAB}]_{\circ}=1.0 \times 10^{-4} \mathrm{~mol} \mathrm{dm}^{-3} ;[\text { Indole }]_{\circ}=1.0 \times 10^{-3} \mathrm{~mol} \mathrm{dm}^{-3} ;} \\
{[\mathrm{NaOH}]=2.0 \times 10^{-3} \mathrm{~mol} \mathrm{dm}^{-3} ;[\text { catalyst }]=2.0 \times 10^{-6} \mathrm{~mol}} \\
\mathrm{dm}^{-3} ; I=0.3 \mathrm{~mol} \mathrm{dm}{ }^{-3}[\text { in the case of Os(VIII) and Ru(III) }+ \text { Os(VIII) } \\
\text { catalysis }] .\end{array}$} \\
\hline
\end{tabular}

$\left(E_{\mathrm{a}}, \Delta H^{\neq}, \Delta G^{\neq}, \Delta S^{\neq}\right.$and $\log A$ ) for the composite reaction were deduced. All these data are summarized in Table 6.

\section{Effect of Varying Benzenesulfonamide Concentrations on the Rate}

Addition of benzenesulfonamide (BSA; $1.0 \times 10^{-3}$ to $8.0 \times$ $10^{-3} \mathrm{~mol} \mathrm{dm}^{-3}$ ), a reduction product of $B A B$, to the reaction mixture did not affect the rate significantly. This indicates that BSA is not involved in any step prior to the rate-limiting step in the schemes proposed.

\section{Effect of Varying Halide Ion Concentrations on the Rate}

The rate remained unchanged with the addition of $\mathrm{Cl}^{-}$or $\mathrm{Br}^{-}$ions in the form of $\mathrm{NaCl}$ and $\mathrm{NaBr}\left(1.0 \times 10^{-2}\right.$ to $\left.8.0 \times 10^{-2} \mathrm{~mol} \mathrm{dm}^{-3}\right)$. These results showed that halide ions play no role in the reaction.

\section{Test for Free Radicals}

The addition of the reaction mixtures to the aqueous acrylaminde monomer solution did not initiate polymerization indicating the absence of in situ formation of free radical species in the reaction sequence. The control experiments were also performed under the same reaction conditions but without the oxidant, BAB.

\section{Discussion}

\section{Reactive Species of Bromamine-B}

Investigations of Morris et al., ${ }^{[18]}$ Bishop and Jennings, ${ }_{1}^{[19]}$ Pryde and Soper ${ }^{[20]}$ and Hardy and Johnston ${ }^{[21]}$ have shown the existence of similar equilibria of $\mathrm{N}$-metallo- $\mathrm{N}$-arylhalosulfonamides in aqueous media. Bromamine-B, like chloramine- $T$, acts as an oxidizing agent in both acidic and alkaline solutions. Depending on the $\mathrm{pH}, \mathrm{BAB}$ exhibits different equilibria in aqueous solutions. ${ }^{[18-21]}$ In alkaline solutions of $\mathrm{BAB}, \mathrm{PhSO}_{2} \mathrm{NBr}_{2}$ does not exist, ${ }^{[8]}$ and the possible oxidizing species are $\mathrm{PhSO}_{2} \mathrm{NBr}^{-}$and $\mathrm{OBr}^{-}$anions, which could be transformed into the more reactive species $\mathrm{PhSO}_{2} \mathrm{NHBr}$ and $\mathrm{HOBr}$ during the course of the reaction in alkali-retarding steps. Several workers have observed the retarding effect of $\mathrm{OH}^{-}$ions on the rate of haloamines with a number of substrates ${ }^{[22-27]}$ and have suggested that the reactivity of weakly alkaline solutions of haloamines is due to the formation of the conjugate acid $\mathrm{PhSO}_{2} \mathrm{NHBr}$ from $\mathrm{PhSO}_{2} \mathrm{NBr}^{-}$in the $\mathrm{OH}^{-}$retarding step. However, in the present investigations, the $\mathrm{OH}^{-}$ions increase the rate of the reaction, clearly indicating $\mathrm{PhSO}_{2} \mathrm{NBr}^{-}$as the reactive oxidizing species. In our earlier work ${ }^{[28,29]}$ the positive influence of $\mathrm{OH}^{-}$ion on the rate of haloamine reactions with a number of substrates has been observed and $\mathrm{RNX}^{-}\left(\mathrm{R}=\mathrm{Ts}\right.$ or $\mathrm{PhSO}_{2} ; \mathrm{X}=\mathrm{Cl}$ or $\mathrm{Br}$ ) suggested as the reactive oxidizing species. In the present investigations, the rate of the reaction accelerated by $\mathrm{OH}^{-}$ions clearly indicates that the anion $\mathrm{PhSO}_{2} \mathrm{NBr}^{-}$is the most likely reactive species involved in the synthesis of anthranilic acids from indoles by BAB in all three catalyzed reactions.

\section{Mechanism and Rate Law of Ru(III) Catalysis}

$\mathrm{Ru}$ (III) chloride acts as catalyst in many organic reactions, particularly in an alkaline medium. ${ }^{[30-33]}$ Under the experimental conditions $\left[\mathrm{OH}^{-}\right] \gg[\mathrm{Ru}(\mathrm{III})]$ and owing to the fact that $\left[\mathrm{OH}^{-}\right]$ increases the rate, ruthenium (III) is predominantly present as the hydroxylated species $\left[\mathrm{Ru}\left(\mathrm{H}_{2} \mathrm{O}\right)_{5} \mathrm{OH}\right]^{2+}$ and its formation is shown in the following equilibrium:

$$
\left[\mathrm{Ru}\left(\mathrm{H}_{2} \mathrm{O}\right) 6\right]^{3+}+\mathrm{OH}^{-} \rightleftharpoons\left[\mathrm{Ru}\left(\mathrm{H}_{2} \mathrm{O}\right)_{5}(\mathrm{OH})\right]^{2+}+\mathrm{H}_{2} \mathrm{O}
$$

Similar equilibria have been reported between $\mathrm{Ru}$ (III) catalyzed reactions in alkaline medium. ${ }^{[31,33]}$

The existence of a complex between the catalyst and BAB was evidenced from the UV-vis spectra of both $\mathrm{Ru}(\mathrm{III})$ and $\mathrm{Ru}(\mathrm{III})-\mathrm{BAB}$ 
mixture. Absorption maxima of $\mathrm{Ru}(\mathrm{III})$ in $\mathrm{HCl}$ medium, $\mathrm{BAB}$ and $\mathrm{Ru}(\mathrm{III})-\mathrm{BAB}$ in aqueous alkaline acetonitrile medium appear at 352,223 and $338 \mathrm{~nm}$ respectively. A hypsochromic shift of $14 \mathrm{~nm}$ from 352 to $338 \mathrm{~nm}$ of $\mathrm{Ru}$ (III) indicates the formation of complex between $\mathrm{Ru}(\mathrm{III})$ and $\mathrm{BAB}$.

Further, for a general equilibrium (3)

$$
\text { Catalyst }+n \mathrm{~S} \stackrel{K}{\rightleftharpoons}\left(\text { Catalyst } \mathrm{S}_{n}\right)
$$

between two metal species, $M$ and $\mathrm{MS}_{n}$ having different extinction coefficients, Ardon ${ }^{[34]}$ has derived the following equation (4):

$$
\frac{1}{\Delta A}=\left(\frac{1}{[S]^{n}}\right) \frac{1}{(\Delta E) K[\text { Catalyst }]_{\text {Total }}}+\frac{1}{(\Delta E)[\text { Catalyst }]_{\text {Total }}}
$$

where $K$ is the formation constant of the complex, $[S]$ is the concentration of $\mathrm{BAB}, \Delta E$ is the difference in extinction coefficient between two metal species, [Catalyst] $]_{\text {Total }}$ is the total concentration of catalyst species and $\Delta A$ is the absorbance difference of solution containing with and without BAB. Equation (4) is valid provided that $[B A B]$ is much greater than $[\text { Catalyst }]_{\text {Total }}$. ACcording to equation (4), a plot of $1 / \Delta A$ vs $1 /[B A B]$ or $1 /[B A B]^{2}$ should be linear with an intercept in the case of $1: 1$ or $1: 2$ type of complex formation between $M$ and $S$. The ratio of intercept to slope of this linear plot gives the value of $K$.

Ruthenium (III) in aqueous alkaline acetonitrile medium containing BAB showed an absorption peak at $338 \mathrm{~nm}$ ( $\lambda_{\max }$ for the complex). The complex formation studies were made at this $\lambda_{\max }$ of $338 \mathrm{~nm}$. In a set of experiments, the solutions were prepared by taking different amounts of $B A B\left(2.0 \times 10^{-4}-4.0 \times 10^{-3} \mathrm{~mol} \mathrm{dm}^{-3}\right)$ at constant amounts of $\mathrm{RuCl}_{3}\left(2.0 \times 10^{-6} \mathrm{~mol} \mathrm{dm}^{-3}\right)$ and $\mathrm{NaOH}$ $\left(2.0 \times 10^{-2} \mathrm{~mol} \mathrm{dm}^{-3}\right)$ in aqueous acetonitrile at $313 \mathrm{~K}$. The absorbance of these solutions was measured at $338 \mathrm{~nm}$. The absorbance of the solution in the absence of BAB was also measured at the same wavelength. The difference of these absorbances (with and without $\mathrm{BAB}$ ) gives the differential absorbance, $\triangle A$. $\mathrm{A}$ plot of $1 / \triangle A$ vs $1 /[B A B]$ was linear with an intercept suggesting the formation of a 1:1 complex between $B A B$ and Ru(III) catalyst. Similar behavior for the formation of complex has been reported in earlier works. ${ }^{[34,35]}$ Further, the plot of log $(1 / \Delta A)$ vs $\log (1 /[B A B])$ was also linear $(r=0.9801)$. From the slope and intercept of the plot $1 / \triangle A$ vs $1 /[B A B]$, the value of the formation constant, $K$, of the complex was deduced and found to be $6.06 \times 10^{2}$.

In view of the above observations, a general mechanism (Scheme 3) is proposed for the Ru(III)-catalyzed synthesis of anthranilic acids from indoles by BAB to account for the observed experimental results.
Here, $\mathrm{X}$ and $\mathrm{X}^{\prime}$ are the intermediate complexes whose structures are illustrated in Scheme 4, where a detailed mechanistic interpretation of indole-BAB reaction in presence $\mathrm{Ru}(\mathrm{III})$ has been proposed.

If $[B A B]_{t}$ represents the total effective concentration of $B A B$, then

$$
[\mathrm{BAB}]_{t}=\left[\mathrm{PhSO}_{2} \mathrm{NHBr}\right]+\left[\mathrm{PhSO}_{2} \mathrm{NBr}^{-}\right]+[\mathrm{X}]
$$

By substituting for $\left[\mathrm{PhSO}_{2} \mathrm{NHBr}\right]$ and $\left[\mathrm{PhSO}_{2} \mathrm{NBr}^{-}\right]$into equation (5) and solving for [X] we get:

$$
[\mathrm{X}]=\frac{\mathrm{K}_{1} \mathrm{~K}_{2}[\mathrm{BAB}]_{\mathrm{t}}\left[\mathrm{OH}^{-}\right][\mathrm{Ru}(\mathrm{III})]}{\left[\mathrm{H}_{2} \mathrm{O}\right]+\mathrm{K}_{1}\left[\mathrm{OH}^{-}\right]+\mathrm{K}_{1} \mathrm{~K}_{2}\left[\mathrm{OH}^{-}\right][\mathrm{Ru}(\mathrm{III})]}
$$

From the slow and rate-determining step of Scheme 3, the rate of reaction is given by

$$
\text { Rate }=-\mathrm{d}[\mathrm{BAB}] / \mathrm{d} t=k_{3}[\text { Indole }][\mathrm{X}]
$$

On substituting the value of [X] from equation (6) into equation (7), one obtains the rate law (8):

$$
\text { Rate }=\frac{-\mathrm{d}[\mathrm{BAB}]}{\mathrm{dt}}=\frac{K_{1} K_{2} k_{3}[\mathrm{BAB}]_{t}[\text { Indole }]\left[\mathrm{OH}^{-}\right][\mathrm{Ru}(\mathrm{III})]}{\left[\mathrm{H}_{2} \mathrm{O}\right]+K_{1}\left[\mathrm{OH}^{-}\right]+K_{1} K_{2}\left[\mathrm{OH}^{-}\right][\mathrm{Ru}(\mathrm{III})]}
$$

Rate law (8) is in complete agreement with experimental data. Hence the proposed mechanism is valid.

Since rate $=k^{\prime}[\mathrm{BAB}]_{t}$, rate law (8) can be transformed into the following equations (9)-(12):

$$
\begin{aligned}
k^{\prime}= & \frac{K_{1} K_{2} k_{3}[\text { Indole }]\left[\mathrm{OH}^{-}\right][\mathrm{Ru}(\mathrm{III})]}{\left[\mathrm{H}_{2} \mathrm{O}\right]+K_{1}\left[\mathrm{OH}^{-}\right]+K_{1} K_{2}\left[\mathrm{OH}^{-}\right][\mathrm{Ru}(\mathrm{III})]} \\
\frac{1}{k^{\prime}}= & \frac{\left[\mathrm{H}_{2} \mathrm{O}\right]}{K_{1} K_{2} k_{3}[\text { Indole }]\left[\mathrm{OH}^{-}\right][\mathrm{Ru}(\mathrm{III})]} \\
& +\frac{1}{K_{2} k_{3}[\text { Indole }][\mathrm{Ru}(\mathrm{III})]}+\frac{1}{k_{3}[\text { Indole }]} \\
\frac{1}{k^{\prime}}= & \frac{1}{\left[\mathrm{OH}^{-}\right]}\left\{\frac{\left[\mathrm{H}_{2} \mathrm{O}\right]}{K_{1} K_{2} k_{3}[\text { Indole }][\mathrm{Ru}(\mathrm{III})]}\right\} \\
& +\left\{\frac{1}{K_{2} k_{3}[\text { Indole }][\mathrm{Ru}(\mathrm{III})]}+\frac{1}{k_{3}[\text { Indole }]}\right\} \\
\overline{k^{\prime}}= & \frac{1}{[\mathrm{Ru}(\mathrm{III})]}\left\{\frac{\left[\mathrm{H}_{2} \mathrm{O}\right]}{K_{1} K_{2} k_{3}[\text { Indole }]\left[\mathrm{OH}^{-}\right]}+\frac{1}{K_{2} k_{3}[\text { Indole }]}\right\} \\
& +\frac{1}{k_{3}[\text { Indole }]}
\end{aligned}
$$

$$
\begin{array}{cll}
\mathrm{PhSO}_{2} \mathrm{NHBr}+\mathrm{OH}^{-} & \stackrel{K_{1}}{\rightleftharpoons} \mathrm{PhSO}_{2} \mathrm{NBr}^{-}+\mathrm{H}_{2} \mathrm{O} & \text { (i) fast } \\
\mathrm{PhSO}_{2} \mathrm{NBr}^{-}+\mathrm{Ru}(\mathrm{III}) & \stackrel{K_{2}}{\rightleftharpoons} \mathrm{X} & \text { (ii) fast }
\end{array}
$$$$
\mathrm{X}+\text { Indole } \stackrel{k_{3}}{\longrightarrow} \mathrm{X}^{\prime}
$$$$
\text { (iii) slow and rds }
$$$$
\mathrm{X}^{\prime}+2 \mathrm{PhSO}_{2} \mathrm{NBr}^{-} \stackrel{k_{4}}{\longrightarrow} \text { Products }
$$

Scheme 3. Ru(III)-catalyzed mechanistic scheme. 


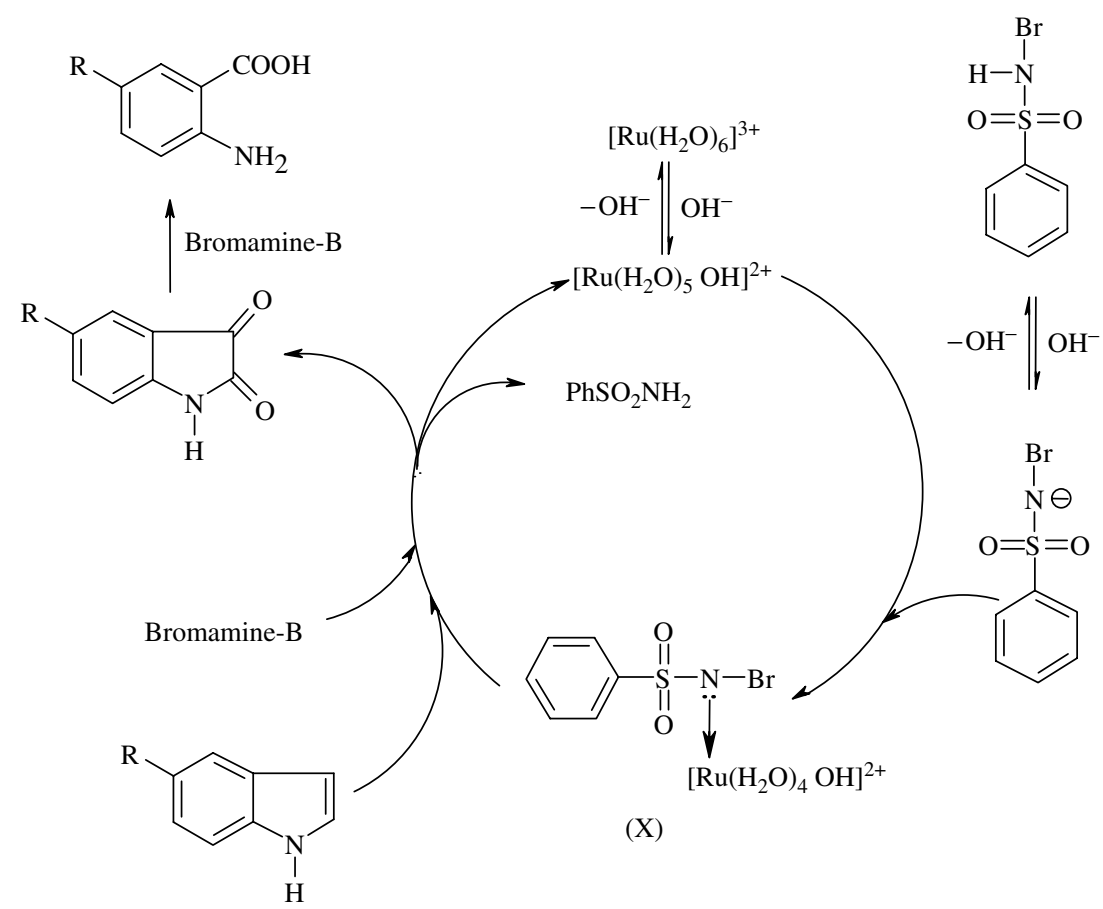

Scheme 4. Ru(III)-catalyzed mechanism for the synthesis of anthranilic acids.

A plot of $1 / k^{\prime}$ vs $1 /\left[\mathrm{OH}^{-}\right]$from equation (11) yields

$$
\begin{aligned}
\text { Slope }= & \frac{\left[\mathrm{H}_{2} \mathrm{O}\right]}{K_{1} K_{2} k_{3}[\text { Indole }][\mathrm{Ru}(\mathrm{III})]} \quad \text { and Intercept } \\
& =\frac{1}{K_{2} k_{3}[\text { Indole }][\mathrm{Ru}(\mathrm{III})]}+\frac{1}{k_{3}[\text { Indole }]}
\end{aligned}
$$

Similarly, a plot of $1 / k^{\prime}$ vs $1 /[\mathrm{O}$ (VIII)] from equation (12) yields

$$
\begin{aligned}
\text { Slope }= & \frac{\left[\mathrm{H}_{2} \mathrm{O}\right]}{K_{1} K_{2} k_{3}[\text { Indole }]\left[\mathrm{OH}^{-}\right]}+\frac{1}{K_{2} k_{3}[\text { Indole }]} \\
& \text { and Intercept }=\frac{1}{\left.k_{3} \text { [Indole }\right]}
\end{aligned}
$$

Therefore from the slopes and intercepts of equations (11) and (12), the values of equilibrium constants $K_{1}$ and $K_{2}$ and decomposition constant $k_{3}$ were calculated for the standard run with $[B A B]_{0}=1.0 \times 10^{-4} \mathrm{~mol} \mathrm{dm}^{-3}$; [Indole] $=1.0 \times$ $10^{-3} \mathrm{~mol} \mathrm{dm}^{-3} ;[\mathrm{NaOH}]=2.0 \times 10^{-3} \mathrm{~mol} \mathrm{dm}^{-3}[\mathrm{Ru}(\mathrm{III})]=$ $2.0 \times 10^{-6} \mathrm{~mol} \mathrm{dm}-3$ at $313 \mathrm{~K}$. The values obtained were $k_{3}=6.14 \times 10^{-2} \mathrm{~s}^{-1} ; K_{2}=8.00 \times 10^{5} \mathrm{dm}^{3} \mathrm{~mol}^{-1} ; K_{1}=$ $7.89 \times 10^{-3} \mathrm{dm}^{3} \mathrm{~mol}^{-1}$.

The proposed Scheme 3 and the derived rate law (8) are substantiated by the experimental observations discussed below.

For a reaction involving a fast pre-equilibrium $\mathrm{H}^{+}$or $\mathrm{OH}^{-}$ ion transfer, the rate increases in $\mathrm{D}_{2} \mathrm{O}$ since $\mathrm{D}_{3} \mathrm{O}^{+}$and $\mathrm{OD}^{-}$are $2-3$ times stronger acids and stronger bases, ${ }^{[36,37]}$ respectively, than $\mathrm{H}_{3} \mathrm{O}^{+}$and $\mathrm{OH}^{-}$ions. In the present studies the observed solvent isotope effect of $k^{\prime}\left(\mathrm{H}_{2} \mathrm{O}\right) / k^{\prime}\left(\mathrm{D}_{2} \mathrm{O}\right)<1$ is due to the greater basicity of $\mathrm{OD}^{-}$compared twith $\mathrm{OH}^{-}$. This isotope effect observed in the present case confirms to the above fact. However, the magnitude of increase of rate in $\mathrm{D}_{2} \mathrm{O}$ is small $\left[k^{\prime}\left(\mathrm{H}_{2} \mathrm{O}\right) / k^{\prime}\left(\mathrm{D}_{2} \mathrm{O}\right)=\right.$ 0.71 ] compared with the expected value of $2-3$ times greater, which can be attributed to the fractional-order dependence of rate on $\left[\mathrm{OH}^{-}\right]$.
It was felt reasonable to compare the reactivity of $B A B$ towards indole in the absence of $\mathrm{Ru}$ (III) catalyst under identical experimental conditions in order to evaluate the catalytic efficiency of $\mathrm{Ru}(\mathrm{III})$. The reactions were carried out at different temperatures $(303-323 \mathrm{~K})$ and from the plot of log $k^{\prime}$ vs $1 / \mathrm{T}$ (Fig. 4), activation parameters were also evaluated for the uncatalyzed reactions (Table 6). However, the Ru(III)-catalyzed reactions were found to be about 6 times faster than uncatalyzed reactions. The activation parameters evaluated for the catalyzed and uncatalyzed reactions explain the catalytic effect on the reaction. The catalyst $\mathrm{Ru}(\mathrm{III})$ forms a complex $(X)$ with the $B A B$, which increases the reactivity of $B A B$.

The general equation relating for uncatalyzed and catalyzed reactions has been derived by Moelwyn and Hughes ${ }^{[38]}$ as:

$$
k_{1}=k_{\mathrm{o}}+K_{\mathrm{C}}[\text { catalyst }]^{x}
$$

Here $k_{1}$ is the observed pseudo first-order rate constant obtained in the presence of $\mathrm{Ru}(\mathrm{III})$ catalyst, $k_{\mathrm{O}}$ is the pseudo first-order constant for the uncatalyzed reaction, $K_{C}$ is the catalytic constant and $x$ is the order of the reaction with respect to $[\mathrm{Ru}(\mathrm{III})]$. In the present investigations, $x$ was found to be 0.8 . Then the value of $K_{C}$ was calculated using the equation (13). The values of $K_{C}$ were evaluated at different temperatures $(303-323 \mathrm{~K})$ and $K_{C}$ was found to vary with temperature. Further, a plot of log $K_{C}$ vs $1 / T$ (Fig. 5) was linear and the values of energy of activation and other activation parameters for the Ru(III) catalyst were computed and are summarized in Table 7.

The proposed mechanism is supported by the observed moderate values of energy of activation and other thermodynamic parameters. The high positive values of the free energy of activation and of the enthalpy of activation suggest that the transition state is highly solvated, while fairly high negative entropy of activation (Table 6) indicates the formation of a rigid associated transition state. Variation of ionic strength of the 


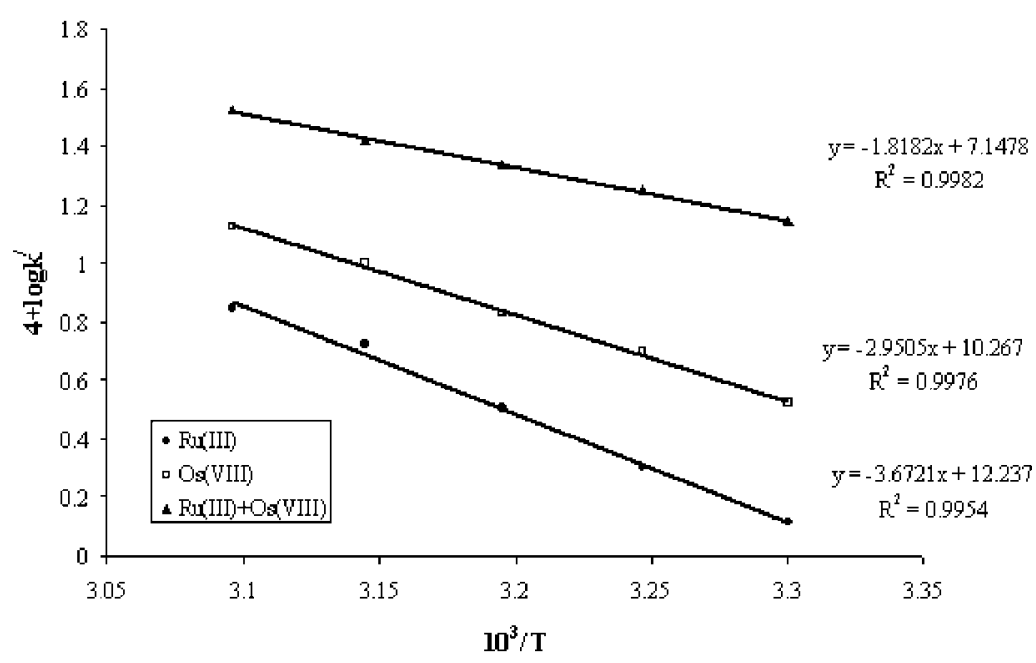

Figure 4. Plots of logk' versus $1 / \mathrm{T}$.

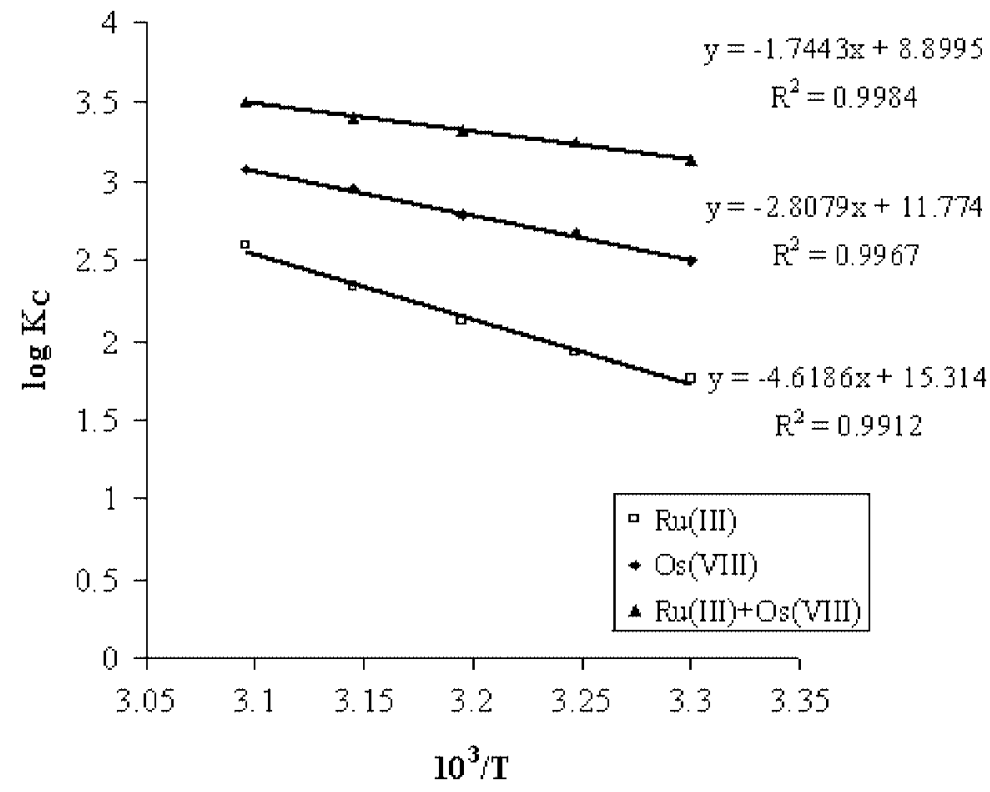

Figure 5. Plots of $\log K_{C}$ vs. 1/T.

medium did not alter the reaction rate, which indicates that the noninvolvement of ionic species in the rate-determining step. Addition of the reduction product of $B A B, B S A$, does not influence the rate, showing that it is not involved in pre-equilibrium. Addition of halide ions has no effect on the rate, indicating that there is no role for halide ions in the reaction. All these observations also confirm the proposed mechanism and derived rate law.

\section{Mechanism and Rate Law of Os (VIII) Catalysis}

It has been shown that osmium has a stable +8 oxidation state ${ }^{[14,39,40]}$ and exists in the following equilibria in alkaline solutions:

$$
\begin{aligned}
& \mathrm{OsO}_{4}+\mathrm{OH}^{-}+\mathrm{H}_{2} \mathrm{O} \rightleftharpoons\left[\mathrm{OsO}_{4}(\mathrm{OH}) \mathrm{H}_{2} \mathrm{O}\right]^{-} \\
& {\left[\mathrm{OsO}_{4}(\mathrm{OH}) \mathrm{H}_{2} \mathrm{O}\right]^{-}+\mathrm{OH}^{-} \rightleftharpoons\left[\mathrm{OsO}_{4}(\mathrm{OH})_{2}\right]^{2-}+\mathrm{H}_{2} \mathrm{O}}
\end{aligned}
$$

The complexes $\left[\mathrm{OsO}_{4}(\mathrm{OH})\left(\mathrm{H}_{2} \mathrm{O}\right)\right]^{-}$and $\left[\mathrm{OsO}_{4}(\mathrm{OH})_{2}\right]^{2-}$, which can be reduced to $\left[\mathrm{OsO}_{2}(\mathrm{OH})_{4}\right]^{2-}$, with octahedral geometries are less likely to form species of higher coordination. It is more realistic to postulate that $\mathrm{OsO}_{4}$, which has tetrahedral geometry, as the active catalyst species can effectively form a complex.

The existence of a complex between indole and Os(VIII) was evidenced from the UV-vis spectra of indole, Os(VIII) and indole-Os(VIII) mixture. Absorption maxima in aqueous alkaline acetonitrile medium appeared at $286 \mathrm{~nm}$ for indole, $319 \mathrm{~nm}$ for $\mathrm{Os}(\mathrm{VIII})$ and $300 \mathrm{~nm}$ for a mixture of both. A bathochromic shift of $14 \mathrm{~nm}$ from 286 to $300 \mathrm{~nm}$ of indole suggests that complexation occurred between indole and Os(VIII). According to equation (4) a plot of $1 / \Delta A$ vs $1 /$ [Indole] with an intercept suggests the formation of $1: 1$ complex between Os(VIII) and indole. Further, the plot of $\log 1 / \Delta A$ vs $\log 1 /[$ Indole] was also linear $(r=9898)$. From the slope and intercept of the plot $1 / \Delta A$ vs $1 /$ [Indole], the value of formation constant, $K$, of the complex was found to be $8.23 \times 10^{2}$.

Based on the experimental results, it is likely that $\mathrm{PhSO}_{2} \mathrm{NBr}^{-}$ itself also acts as the reactive oxidant species in the present case. 


\begin{tabular}{|c|c|c|c|}
\hline \multirow[b]{2}{*}{ Temperature (K) } & \multicolumn{3}{|c|}{$K_{C} \times 10$} \\
\hline & $\mathrm{Ru}(\mathrm{III})$ & Os(VIII) & $\begin{aligned} & \mathrm{Ru}(\mathrm{III}) \\
+ & \mathrm{Os}(\mathrm{VIII})\end{aligned}$ \\
\hline 303 & 5.65 & 31.6 & 138 \\
\hline 308 & 8.45 & 46.9 & 172 \\
\hline 313 & 13.4 & 62.8 & 211 \\
\hline 318 & 21.8 & 91 & 255 \\
\hline 323 & 54.3 & 118 & 319 \\
\hline$E_{\mathrm{a}}\left(\mathrm{kJ} \mathrm{mol}^{-1}\right)$ & 88 & 50.6 & 41.8 \\
\hline$\Delta H^{\neq}\left(\mathrm{kJ} \mathrm{mol}^{-1}\right)$ & 85.1 & 47.3 & 38.1 \\
\hline$\Delta G^{\neq}\left(\mathrm{kJ} \mathrm{mol}^{-1}\right)$ & 93.4 & 70.2 & 62.2 \\
\hline$\Delta S^{\neq}\left(\mathrm{JK}^{-1} \mathrm{~mol}^{-1}\right)$ & -70.8 & -52.3 & -45.7 \\
\hline $\log A$ & 13.1 & 8.98 & 5.86 \\
\hline
\end{tabular}

$[B A B]_{\circ}=1.0 \times 10^{-4} \mathrm{~mol} \mathrm{dm}^{-3} ;[\text { Indole }]_{\circ}=1.0 \times 10^{-3} \mathrm{~mol} \mathrm{dm}^{-3} ;$ $[\mathrm{NaOH}]=2.0 \times 10^{-3} \mathrm{~mol} \mathrm{dm}^{-3} ;$ [catalyst $]=2.0 \times 10^{-6} \mathrm{~mol} \mathrm{dm}^{-3}$; $I=0.3 \mathrm{~mol} \mathrm{dm}^{-3}$ [in the case of Os(VIII) and Ru(III) + Os(VIII) catalysis].

Considering the above facts and all the observed experimental data, the following reaction, Scheme 5 , can be suggested for $\mathrm{Os}$ (VIII) catalyzed synthesis of anthranilic acids from indoles by $B A B$ in alkaline medium:

Here, $X^{\prime \prime}$ and $X^{\prime \prime \prime}$ are the intermediate complexes whose structures are given in Scheme 6, wherein a detailed mechanistic pathway for Os(VIII) catalysis reaction is illustrated. The total effective concentration of BAB is given by:

$$
[\mathrm{BAB}]_{t}=\left[\mathrm{PhSO}_{2} \mathrm{NHBr}\right]+\left[\mathrm{PhSO}_{2} \mathrm{NBr}^{-}\right]
$$

From step (ii) of Scheme 5,

$$
\left[\mathrm{X}^{\prime \prime}\right]=K_{6}[\text { Indole }][\mathrm{Os}(\mathrm{VIII})]
$$

From the slow and rate determining step (iii) of Scheme 5, the rate of reaction is given by:

$$
\text { Rate }=-\mathrm{d}[\mathrm{BAB}]_{t} / \mathrm{d} t=k_{7}\left[\mathrm{X}^{\prime \prime}\right]\left[\mathrm{PhSO}_{2} \mathrm{NBr}^{-}\right]
$$

On substituting for $\left[\mathrm{PhSO}_{2} \mathrm{NBr}^{-}\right]$and $\left[\mathrm{X}^{\prime \prime}\right]$ into equation (18), the rate law (19) was obtained:

$$
\text { Rate }=\frac{\left.K_{5} K_{6} k_{7}[\mathrm{BAB}]_{\mathrm{t}}[\text { Indole }]\left[\mathrm{OH}^{-}\right] \mathrm{Os}(\mathrm{VIII})\right]}{\left[\mathrm{H}_{2} \mathrm{O}+K_{5}\left[\mathrm{OH}^{-}\right]\right.}
$$

The rate law (19) is in agreement with the experimentally observed results. Since rate $=k^{\prime}[\mathrm{BAB}]_{t}$, equation (19) can be transformed into equations (20) and (21):

$$
\begin{aligned}
k^{\prime}= & \frac{K_{5} K_{6} k_{7}[\text { Indone }]\left[\mathrm{OH}^{-}\right][\mathrm{Os}(\mathrm{VIII})]}{\left[\mathrm{H}_{2} \mathrm{O}\right]+K_{5}\left[\mathrm{OH}^{-}\right]} \\
\frac{1}{k^{\prime}}= & \frac{\left[\mathrm{H}_{2} \mathrm{O}\right]}{K_{5} K_{6} k_{7}[\text { Indole }][\mathrm{Os}(\mathrm{VIIII})]\left[\mathrm{OH}^{-}\right]} \\
& +\frac{1}{K_{6} k_{7}[\text { Indole }][\mathrm{Os}(\mathrm{VIIII})]}
\end{aligned}
$$

A plot of $1 / k^{\prime}$ vs $1 /\left[\mathrm{OH}^{-}\right]$according to equation (21), with other experimental conditions held constant, was found to be linear $(r>0.9899) . K_{5}$ and $K_{6} k_{7}$ values were calculated from the slope and intercept of such a plot and was found to be $2.67 \times 10^{3}$ and $2.0 \times 10^{-5} \mathrm{dm}^{3} \mathrm{~mol}^{-1} \mathrm{~s}^{-1}$ for the standard run, $[B A B]_{0}=1.0 \times 10^{-4} \mathrm{~mol} \mathrm{dm}^{-3} ;[\text { Indole }]_{\mathrm{o}}=1.0 \times 10^{-3} \mathrm{~mol} \mathrm{dm}^{-3}$; $[\mathrm{Os}(\mathrm{VIII})]=2.0 \times 10^{-6} \mathrm{~mol} \mathrm{dm}^{-3} ;$ and $I=0.3 \mathrm{~mol} \mathrm{dm}^{-3}$ at $313 \mathrm{~K}$. Scheme 5 and rate law (19) can explain the following observed experimental results.

The ionic strength $(I)$ effect on the reaction rates was described according to the theory of Bronsted and Bjerrum, ${ }^{[41]}$ which postulates the reaction through the formation of an activated complex. According to this theory, the effect of ionic strength on the rate for a reaction involving two ions is given by the relationship

$$
\log k^{\prime}=\log k_{\mathrm{o}}+1.02 Z_{\mathrm{A}} Z_{\mathrm{B}} I^{1 / 2}
$$

Here $Z_{A}$ and $Z_{B}$ are the valency of the ions $A$ and $B$, and $k$ and $k_{\mathrm{o}}$ are the rate constants in the presence and absence of the added electrolyte, respectively. A plot of $\log k^{\prime}$ against $I^{1 / 2}$ should be linear with a slope of $1.02 Z_{A} Z_{B}$. If $Z_{A}$ and $Z_{B}$ have similar signs, the quantity $Z_{A} Z_{B}$ is positive and the rate increases with the ionic strength, having a positive slope, while if the ions have dissimilar charges, the quantity $Z_{A} Z_{B}$ is negative and the rate will decrease with the increase in ionic strength, having a negative slope. In the present case, a primary salt effect was observed as the rate increased with the increase in ionic strength of the medium, ${ }^{[44]}$ supporting the involvement of ions of same sign in the rate-limiting step (Scheme 6). The Debye-Huckel plot (log $k^{\prime}$ against $I^{1 / 2}$ ) gave a straight line with a slope of 0.6 . In the present system, a two negative ions $\left(Z_{A}=-1\right.$ and $\left.Z_{B}=-1\right)$ were involved in the rate-determining step and the expected slope of +1 was not found. This may be due to the fact that the ionic strength employed was beyond the formal Debye-Huckel limiting range. Alternatively, there could be formation of ion pairs in concentrated solutions, as suggested by Bjerrum. ${ }^{[4]}$

The reactivity of $\mathrm{BAB}$ towards indole in the absence of Os(VIII) catalyst was compared with the Os(VIII) catalyzed reaction under identical experimental conditions. Rate constants revealed that the Os(VIII) catalyzed reactions were about 13-fold faster than

$$
\begin{aligned}
& \mathrm{PhSO}_{2} \mathrm{NHBr}+\mathrm{OH}^{-} \stackrel{K_{5}}{=} \mathrm{PhSO}_{2} \mathrm{NBr}^{-}+\mathrm{H}_{2} \mathrm{O} \text { (i) fast } \\
& \text { Indole }+ \text { Os(VIII) } \stackrel{K_{6}}{=} \mathrm{X}^{\prime \prime} \quad \text { (ii) fast } \\
& \begin{aligned}
\mathrm{X}^{\prime \prime}+\mathrm{PhSO}_{2} \mathrm{NBr}^{-} \stackrel{k_{7}}{\longrightarrow} \mathrm{X}^{\prime \prime \prime} & \text { (iii) slow and rds } \\
\mathrm{X}^{\prime \prime \prime}+\mathrm{PhSO}_{2} \mathrm{NBr}^{-} \stackrel{k_{8}}{\longrightarrow} \text { Products } & \text { (iv) fast }
\end{aligned}
\end{aligned}
$$

Scheme 5. Os(VIII)-catalyzed mechanistic scheme. 


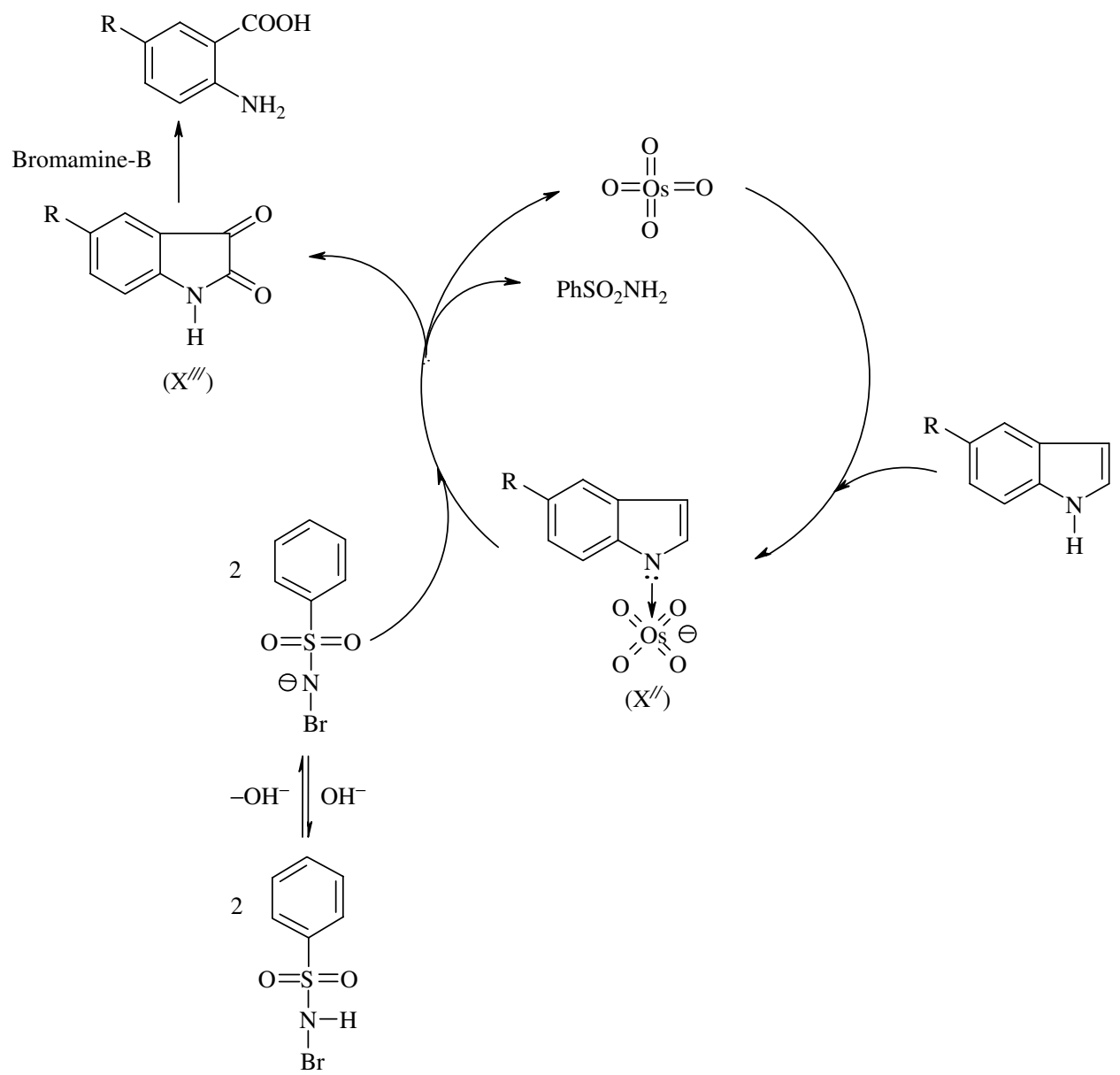

Scheme 6. Os(VIII)-catalyzed mechanism for the synthesis of anthranilic acids.

uncatalyzed reactions (Table 6). The values of $K_{C}$ were determined at different temperatures and, from a plot of log $K_{C}$ vs $1 / T$, the values of activation parameters for Os(VIII) catalyst were computed (Table 7). The negligible effect of the addition of BSA and halide ions on the rate of the reaction and also activation parameters was in good agreement with the mechanism proposed and the rate law derived.

\section{Mechanism and Rate Law of Ru(III) + Os (VIII) Catalysis}

The kinetic data suggested that $\mathrm{PhSO}_{2} \mathrm{NBr}^{-}$is also the reactive species of $B A B$ in $\mathrm{Ru}(\mathrm{III})+\mathrm{Os}(\mathrm{VIII})$ catalyzed reaction. UV-visible spectral studies revealed that there is transient existence of a complex between $\mathrm{Ru}(\mathrm{III})$ and $\mathrm{Os}$ (VIII) in aqueous alkaline acetonitrile medium. Absorption maxima in aqueous alkaline acetonitrile medium appeared at $352 \mathrm{~nm}$ for $\mathrm{Ru}(\mathrm{III}), 319 \mathrm{~nm}$ for Os(VIII) and $336 \mathrm{~nm}$ for a mixture of both. This clearly indicates the formation of a transient complex between $\mathrm{Ru}(\mathrm{III})$ and $\mathrm{Os}(\mathrm{VIII})$ and this transient complex $[\mathrm{Ru}(\mathrm{III})+\mathrm{Os}(\mathrm{VIII})]$ acts as reactive catalyst species in this case.

The existence of other complex between $\mathrm{Ru}(\mathrm{III})+\mathrm{Os}(\mathrm{VIII})$ and $B A B$ was also evidenced from the UV - vis spectra of both $B A B, R u(I I I)$ $+\mathrm{Os}(\mathrm{VIII})$ and a mixture of both in alkaline medium. Absorption maxima in aqueous alkaline acetonitrile medium appeared at $223 \mathrm{~nm}$ for $\mathrm{BAB}, 336 \mathrm{~nm}$ for Os(VIII) and $245 \mathrm{~nm}$ for a mixture of both.
From the above preceding discussions, Scheme 7 has been proposed to account for the observed kinetic results. In this scheme, $\mathrm{X}^{\mathrm{IV}}$ and $\mathrm{X}^{\mathrm{V}}$ represent the complex intermediate species. Scheme 8 depicts the mode of indole-BAB reaction in the presence of $\mathrm{Ru}$ (III) $+\mathrm{Os}(\mathrm{VIII})$ mixture. The total effective concentration of $\mathrm{BAB}$ is

$$
[\mathrm{BAB}]_{t}=\left[\mathrm{PhSO}_{2} \mathrm{NHBr}\right]+\left[\mathrm{PhSO}_{2} \mathrm{NBr}^{-}\right]
$$

From the slow step of Scheme 7,

$$
\text { rate }=-\mathrm{d}[\mathrm{BAB}]_{t}=k_{10}\left[\mathrm{PhSO}_{2} \mathrm{NBr}^{-}\right][\mathrm{Ru}(\mathrm{III})+\mathrm{Os}(\mathrm{VIII})]
$$

By substituting for $\left[\mathrm{PhSO}_{2} \mathrm{NBr}^{-}\right]$into equation (24) the following rate law is obtained:

$$
\text { rate }=\frac{-\mathrm{d}[\mathrm{BAB}]_{t}}{\mathrm{~d} t}=\frac{K_{9} k_{10}[\mathrm{BAB}]_{t}[\mathrm{Ru}(\mathrm{III})+\mathrm{Os}(\mathrm{VIII})]\left[\mathrm{OH}^{-}\right]}{\left[\mathrm{H}_{2} \mathrm{O}\right]+K_{9}\left[\mathrm{OH}^{-}\right]}
$$

Rate law (25) is in good agreement with the experimental data.

Since rate $=k^{\prime}[\mathrm{BAB}]_{t}$, equation (25) can be transformed into equations (26) and (27):

$$
\begin{aligned}
k^{\prime}= & \frac{K_{9} k_{10}[\mathrm{Ru}(\mathrm{III})+\mathrm{Os}(\mathrm{VIII})]\left[\mathrm{OH}^{-}\right]}{\left[\mathrm{H}_{2} \mathrm{O}\right]+K_{9}\left[\mathrm{OH}^{-}\right]} \\
\frac{1}{k^{\prime}}= & \frac{\left[\mathrm{H}_{2} \mathrm{O}\right]}{K_{9} k_{10}\left[\mathrm{Ru}(\mathrm{III}+\mathrm{Os}(\mathrm{VIIII})]\left[\mathrm{OH}^{-}\right]\right.} \\
& +\frac{1}{k_{9}[\mathrm{Ru}(\mathrm{III})+\mathrm{Os}(\mathrm{VIII})]}
\end{aligned}
$$




$$
\begin{array}{rlr}
\mathrm{PhSO}_{2} \mathrm{NHBr}+\mathrm{OH}^{-} \stackrel{K_{9}}{\rightleftharpoons} \mathrm{PhSO}_{2} \mathrm{NBr}^{-}+\mathrm{H}_{2} \mathrm{O} & \text { (i) fast } \\
\mathrm{PhSO}_{2} \mathrm{NBr}^{-}+[\mathrm{Ru}(\mathrm{III})+\mathrm{Os}(\mathrm{VIII})] \stackrel{k_{10}}{\longrightarrow} \mathrm{X}^{\mathrm{IV}} & \text { (ii) slow and rds } \\
\mathrm{X}^{\mathrm{IV}}+\text { Indole } \stackrel{k_{11}}{\longrightarrow} \mathrm{X}^{\mathrm{V}} & \text { (iii) fast } \\
\mathrm{X}^{\mathrm{V}}+\mathrm{PhSO}_{2} \mathrm{NBr}^{-} \stackrel{k_{12}}{\longrightarrow} \text { Products } & \text { (iv) fast }
\end{array}
$$

Scheme 7. Ru(III)+Os(VIII)-catalyzed mechanistic scheme.

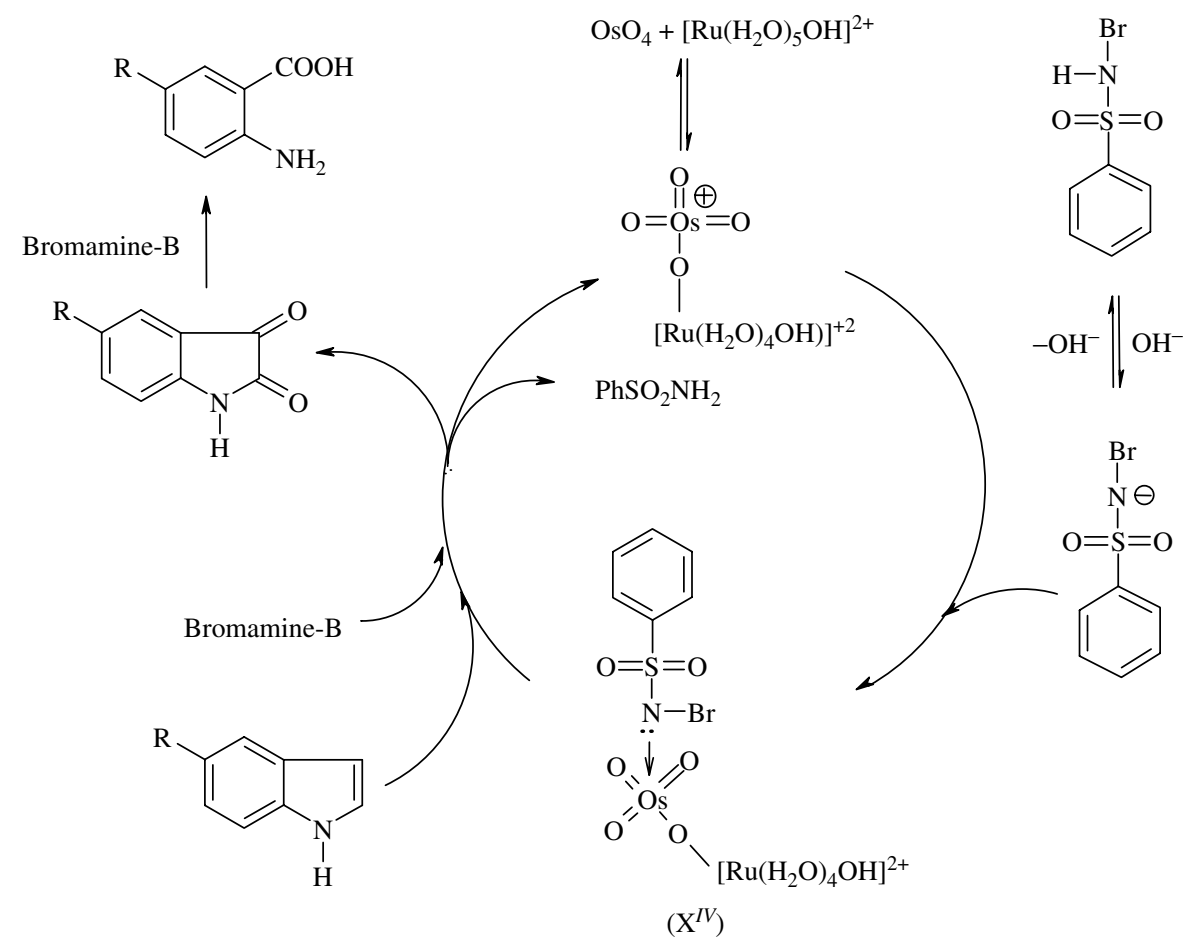

Scheme 8. Ru(III) + Os(VIII)-catalyzed mechanism for the synthesis of anthranilic acids.

Based on equation (27), a plot of $1 / k^{\prime}$ vs $1 /\left[\mathrm{OH}^{-}\right]$at constant $[\mathrm{BAB}]_{0},[\text { Indole }]_{0},[\mathrm{Ru}(\mathrm{III})+\mathrm{Os}(\mathrm{VIII})]$ ionic strength and temperature was found to be linear ( $r=0.9899)$. From the values of slope and intercept of such a plot, the equilibrium constant $\left(K_{9}\right)$ and decomposition constant $\left(k_{10}\right)$ were calculated and found to be $2.35 \times 10^{4} \mathrm{dm}^{3} \mathrm{~mol}^{-1}$ and $1.26 \times 10^{-2} \mathrm{~s}^{-1}$ respectively.

The proposed mechanism and the derived rate law were substantiated by the following experimental facts. The ionic strength $(I)$ effect on the reaction rates was studied and a primary salt effect was observed as the rate decreases with increase in ionic strength of the medium, ${ }^{[41]}$ supporting the involvement of ions of opposite sign in the rate-determining step (Scheme 8). The Debye-Huckel plot (log $k^{\prime}$ against $\mathrm{I}^{1 / 2}$ ) gave straight line with slope of -1.60 . In the present system, a negatively charge ion and two positively charged ions were involved in the rate-determining step (Scheme 8) and the expected slope of -2 was not found. This may be due to the fact that the ionic strength employed was beyond the formal Debye-Huckel limiting range. Alternatively, there could be formation of ion pairs in concentrated solutions, as suggested by Bjerrum. ${ }^{[4]}$

The reactions were also studied in absence of $\mathrm{Ru}(\mathrm{III})+\mathrm{Os}(\mathrm{VIII})$ catalyst and rates were compared with that of $\mathrm{Ru}(\mathrm{III})+\mathrm{Os}(\mathrm{VIII})$ catalyzed reaction under identical experimental conditions. Rate constants revealed that the $\mathrm{Ru}(\mathrm{III})+\mathrm{Os}(\mathrm{VIII})$ catalyzed reactions are about 42-fold faster than uncatalyzed reactions (Table 6). The values of $K_{\mathrm{C}}$ were determined at different temperatures and from a plot of $\log K_{C}$ vs $1 / T$; values of activation parameters for $\mathrm{Ru}(\mathrm{III})$ + Os(VIII) catalyst were computed (Table 7). The negligible effect on the addition of BSA and halide ions on the rate of the reaction and also activation parameters was in good agreement with the mechanism proposed and the rate law derived.

The kinetics of all the three catalyzed reactions was compared with uncatalyzed reactions, under similar experimental conditions, and it was found that the catalyzed reactions were 6- to 42-fold faster. For the catalyzed reactions, it is seen from the Table 6 that the activation energy was highest for the slowest reaction and vice-versa. From the inspection of rate constants and the values of energy of activation (Table 6), the relative reactivity of these catalysts was in the order: $\mathrm{Ru}(\mathrm{III})+\mathrm{Os}(\mathrm{VIII})>\mathrm{Os}(\mathrm{VIII})>\mathrm{Ru}(\mathrm{III})$. The reactivity was faster in the case of Os(VIII) compared with $\mathrm{Ru}(\mathrm{III})$. This may be attributed to the d-electronic configuration of the metal ions. Osmium having $d^{\circ}$ electronic configuration has greater catalytic efficiency to oxidize the substrate compared to the Ru(IIII), which is of $d^{5}$ electronic configuration. The reactivity in the case of 
$\mathrm{Ru}(\mathrm{III})+\mathrm{Os}(\mathrm{VIII})$ catalysis was maximum. This trend may be due to the formation of a transient complex between $\mathrm{Ru}(\mathrm{III})$ and Os(VIII). $\mathrm{Ru}$ (III) effectively forms a complex with Os(VIII) which increases the catalytic property of Os(VIII) and thereby the catalytic effect of the mixture of these is greater when compared with the individual catalysts and thus the positive synergistic catalytic activity of $\mathrm{Ru}(\mathrm{III})+\mathrm{Os}(\mathrm{VIII})$ mixture. Therefore the observed reactivity in the present study follows the order: $\mathrm{Ru}(\mathrm{III})+\mathrm{Os}(\mathrm{VIII})>\mathrm{Os}(\mathrm{VIII})>\mathrm{Ru}(\mathrm{III})$. Consequently, we can conclude that the synergistic effect of Ru(III) + Os(VIII) mixture is greater than the sum of their separate effects in the present study.

\section{Conclusion}

$\mathrm{Ru}(\mathrm{III}), \mathrm{Os}(\mathrm{VIII})$ and a mixture of both catalyzed synthesis of anthranilic acids from indoles has been performed efficiently using bromamine- $B$. The aforementioned metal ions were found to be efficient catalysts for the facile synthesis of anthranilic acids in aqueous alkaline acetonitrile medium. Ru(III) $+\mathrm{Os}(\mathrm{VIII})$ serves as an efficient catalyst when compared with the individual catalysts and shows positive synergetic catalytic activity. The stoichiometry and anthranilic acids products of $\mathrm{Ru}(\mathrm{III}), \mathrm{Os}(\mathrm{VIII})$ and $\mathrm{Ru}(\mathrm{III})+$ Os(VIII) catalysis were same but their observed kinetic patterns and mechanistic aspects were different, obeying the underlying rate law:

$$
\begin{aligned}
& \text { rate }=k[\mathrm{BAB}]_{t}[\text { Indole }][\mathrm{Ru}(\mathrm{IIII})]^{x}\left[\mathrm{OH}^{-}\right]^{y} \\
& \text { rate }=k[\mathrm{BAB}]_{t}[\text { Indole }][\mathrm{Os}(\mathrm{VIIII})]\left[\mathrm{OH}^{-}\right]^{y} \\
& \text { rate }=k[\mathrm{BAB}]_{t}[\text { Indole }]^{\mathrm{O}}[\mathrm{Ru}(\mathrm{III})+\mathrm{Os}(\mathrm{VIII})]\left[\mathrm{OH}^{-}\right]^{y}
\end{aligned}
$$

A comparison of the kinetics of the reactions catalyzed by these catalysts, under identical experimental conditions, was found be in the order: $\mathrm{Ru}(\mathrm{III})+\mathrm{Os}(\mathrm{VIII})>\mathrm{Os}(\mathrm{VIII})>\mathrm{Ru}(\mathrm{III})$. Further, under identical experimental conditions, the kinetics of all the three catalyzed reactions were compared with uncatalyzed reactions and were found to proceed 6- to 42-fold faster than the uncatalyzed reactions. Based on the observed experimental results, detailed mechanistic interpretations and the related kinetic modelings were worked out for each catalyst. It can be concluded that Ru(III), Os(VIII) and Ru(III) + Os(VIII) act as efficient catalysts in the synthesis of anthranilic acids from indoles brought about by BAB in alkaline medium and predominantly the synergism of $\mathrm{Ru}(\mathrm{III})+\mathrm{Os}(\mathrm{VIII})$ mixed catalyst is prodigious.

\section{Supporting information}

Supporting information may be found in the online version of this article.

\section{References}

[1] J. K. Joshi, V. R. Patel, K. Patel, Indian J. Chem. Pharm. Sci. 2007, 69, 697.
[2] A. Thorarensen, J. Li, B. D. Wakefield, D. L. Romero, K. R. Marotti, M. T. Sweeney, G. E. Zurenko, Bioorg. Med. Chem. Lett. 2007, 17, 3113.

[3] H. Jan, S. Jan, Collect. Czech. Chem. Commun. 1996, 61, 941.

[4] J. F. M. Silva da, S. J. Garden, A. C. Pinto, J. Braz. Chem. Soc. 2001, 12, 273.

[5] E. Chapman, H. Stephen, J. Chem. Soc. Trans. 1925, 127, 1791.

[6] M. M. Campbell, G Johnson, Chem. Rev. 1978, 78, 65.

[7] E. Kolvari, A. G. Choghamarani, P. Salehi, F. Shirini, M. A. Zolfigol, J. Iran. Chem. Soc. 2007, 4, 126.

[8] R. V. Jagadeesh, Puttaswamy, J. Phys. Org. Chem. 2008, 21, 844.

[9] Puttaswamy, R. V. Jagadeesh, Appl. Catal. A: Gen. 2005, 292, 259.

[10] K. K. Baneji, B. Jayaram, D. S. Mahadevappa, J. Sci. Ind. Res. 1987, 46, 65.

[11] D. H. Bremner, Synth. Reag. 1984, 6, 9 .

[12] K. S. Rangappa, M. P. Ragavendra, D. S. Mahadevappa, D. C. Gowda, J. Org. Chem. 1998, 63, 531.

[13] F. A. Cotton, G. Wilkinson, P. L. Gaus, Basic Inorganic Chemistry, 3rd edn, John Wiley \& Sons Inc.: New York, 1995, p. 600

[14] W. P. Griffith, The Chemistry of Rare Platinum Metals, InterScience: New York, 1967

[15] K. R. Bhat, K. Jyothi, B. T. Gowda, Oxid. Commun. 2002, 25, 117 and references therein.

[16] M. S. Ahmed, D. S. Mahadevappa, Talanta 1980, 27, 669.

[17] A. I. Vogel, Textbook of Quantitative Inorganic Analysis, 4th edn. ELBS-Longman: London, 1978, p. 427.

[18] J. C. Morris, J. R. Salazar, M. A. Winemann, J. Am. Chem. Soc. 1948 70, 2036.

[19] E. Bishop, V. J. Jennings, Talanta 1958, 1, 197.

[20] B. G. Pryde, F. G. Soper, J. Chem. Soc. 1931, 1514; 1926, 1582

[21] F. F. Hardy, J. P. Johnston, J. Chem. Soc. Perkin Trans. 2 1973, 742.

[22] D. S. Mahadevappa, K. S. Rangappa, N. M. M. Gowda, B. T. Gowda, Int. J. Chem. Kinet. 1982, 14, 1183.

[23] S. Meenakshisundaram, R. M. Sockalingam, J. Mol. Catal. A Chem. 2000, 160, 269.

[24] Puttaswamy, Nirmala Vaz, Stud. Surf. Sci. Catal. 2001, 133, 535.

[25] Puttaswamy, R. V. Jagadeesh, Cent. Eur. J. Chem. 2005, 3, 482.

[26] Puttaswamy, Nirmala Vaz, Transition Met. Chem. 2003, 28, 409.

[27] M. H. Kondarasaiah, S. Ananda, Puttaswamy, N. M. M Gowda, Synth. React. 2003, 33, 1145.

[28] Puttaswamy, R. V. Jagadeesh, Int. J. Chem. Kinet. 2005, 37, 201.

[29] Puttaswamy, R. V. Jagadeesh, Ind. Eng. Chem. Res. 2006, 45, 1563.

[30] D. C. Bilehal, R. M. Kulkarni, S. T. Nandibewoor, Can. J. Chem. 2001, 79, 1926.

[31] R. T. Mahesh, M. B. Bellaki, S. T. Nandibewoor, Catal. Lett. 2004, 97, 91.

[32] C. P. Kathari, R. M. Mulla, S. T. Nandibewoor, Oxid. Commun. 2005, $28,579$.

[33] S. A. Chimatdar, T. Basavaraj, S.T. Nandibewoor, Inorg. React. Mechnism. 2002, 4, 209.

[34] M. Ardon, J. Chem. Soc. 1957, 1811.

[35] N. Kambo, S. K. Upadhyay, Indian J. Chem. 2004, 43 A, 1210.

[36] C. J. Collins, N. S. Bowman, Isotope Effects in Chemical Reactions, Van Nostrand Reinhold: New York, 1970, p. 267.

[37] K. B. Wiberg, Chem. Rev. 1955, 55, 713; b) K. B. Wiberg, Physical Organic Chemistry, Wiley: New York, 1964.

[38] E. A. Moelwyn-Hughes, Kinetics of Reaction in Solutions, Oxford University Press: London, 1947, pp. 297.

[39] A. M. Mackay, R. A. Mackay, Introduction to Modern Inorganic Chemistry, 4th edn, Prentice Hall: Englewood Cliffs, NJ, 1989, p. 259.

[40] R. D. Saverbrum, E. B. Sandell, J. Am. Chem. Soc. 1953, 75, 4170.

[41] K. J.Laidler, Chemical Kinetics, 2nd edn. McGraw-Hill: New York, 1965, pp. 219. 